UNIVERSIDADE DE SÃO PAULO

FACULDADE DE MEDICINA DE RIBEIRÃO PRETO

MONIZE VILELA

Desempenho da mímica facial e qualidade de vida na fase aguda da paralisia facial periférica 
MONIZE VILELA

\section{Desempenho da mímica facial e qualidade de vida na fase aguda da paralisia facial periférica}

\section{Versão Corrigida}

Versão original encontra-se na unidade que aloja o Programa de Pós-Graduação

Dissertação apresentada à Faculdade de Medicina de Ribeirão Preto da Universidade de São Paulo para a obtenção do título de Mestre em Ciências Médicas.

Área de Concentração: Morfofisiologia de Estruturas Faciais

Orientadora: $\operatorname{Prof}^{\mathrm{a}} \mathrm{Dr}^{\mathrm{a}}$ Luciana Vitaliano Voi Trawitzki 
Autorizo a reprodução e divulgação total ou parcial deste trabalho, por qualquer meio convencional ou eletrônico, para fins de estudo e pesquisa, desde que citada a fonte.

Vilela, Monize.

Desempenho da mímica facial e qualidade de vida na fase aguda da paralisia facial periférica. Ribeirão Preto, 2019.

99 p. : il. ; $30 \mathrm{~cm}$

Dissertação de Mestrado, apresentada à Faculdade de Medicina de Ribeirão Preto/USP. Área de concentração: Morfofisiologia de Estruturas Faciais.

Orientador: Trawitzki, Luciana Vitaliano Voi.

1. Paralisia facial. 2. Qualidade de vida. 3. Assimetria Facial. 4. Expressão Facial. 5. Paralisia de Bell. 
Nome: Vilela, Monize

Título: Desempenho da mímica facial e qualidade de vida na fase aguda da paralisia facial periférica.

Dissertação apresentada à Faculdade de Medicina de Ribeirão Preto da Universidade de São Paulo para a obtenção do título de Mestre em Ciências Médicas.

Área de Concentração: Morfofisiologia de Estruturas Faciais

Aprovado em:

Banca examinadora:

Prof. (a)

Julgamento:

Prof. (a)

Julgamento:

Prof. (a)

Julgamento:

Prof. (a)

Julgamento:
Instituição

Assinatura:

Instituição

Assinatura:

Instituição

Assinatura:

Instituição

Assinatura: 


\section{DEDICATÓRIA}

A Deus, eterno Pai, que conduz a minha vida, abençoa e ilumina o melhor caminho frente aos desafios, unido à mãe Maria que intercede pelos seus filhos e nunca os desampara.

"Se Deus é por nós, quem será contra nós?"

Romanos 8:31

Aos meus pais, Benedito José e Marcia, meus exemplos de coragem e amor, que em todas as circunstâncias de minha vida foram meu apoio, minha base, não medindo esforços para que eu seja a pessoa que almejo ser, impulsionando a querer mais, a não me contentar com uma vida sem o brilho nos olhos. A vocês eu devo tudo o que sou...

... e tudo o que hei de ser!

Meu amor eterno! 


\section{AGRADECIMENTOS ESPECIAIS}

Agradeço à professora Luciana Vitaliano Voi Trawitzki, que desde a graduação, com seu exemplo de esposa, mãe e profissional, confirmou em mim a escolha pela motricidade orofacial. Agradeço também pela paciência e carinho demonstrado ao longo dos anos seguintes na construção do meu ser pessoal e profissional. Sou imensamente grata.

À professora Cláudia Maria de Felício, por me acolher durante meu trajeto na pós-graduação, por todo o conhecimento transmitido e pela prontidão para o ensino.

Ao professor Eduardo Tanaka Massuda, modelo de profissionalismo e humanidade, a quem admiro e agradeço por sempre me auxiliar em minhas dificuldades.

À minha filhotinha Alice Stahl Gaido, que surgiu na minha vida muito inesperadamente, se tornou uma companheira, uma amiga confiável e minha base sólida nos momentos de tremulação, me mostrou como a vida pode ser mais leve e a sempre acreditar que tudo vai dar certo.

À Franciele Voltarelli da Silva Dias, ser iluminado, de extremo carisma e que se tornou um exemplo de dedicação frente às dificuldades, além de uma ouvinte nos momentos bons e ruins.

Aos meus queridos amigos, de perto e de longe, que sempre muito me apoiaram, acalmaram, e se desdobraram inúmeras vezes para caminhar ao meu lado, tornando esta fase da minha vida renovadora, produtiva e cheia de autoconhecimento.

Às fonoaudiólogas Tais Helena Grechi e Melissa Nara de Carvalho PicinatoPirola, pessoas dotadas de paciência, que durante todo o meu ano de aperfeiçoamento se tornaram conselheiras de vida e referência de 
conhecimento. E à Carina Borges e à Fernanda Vincia Sidequersky, que muito me auxiliaram durante meu aprendizado teórico e prático na paralisia facial.

Aos funcionários do LISE, à querida Luciana Gonçalvez de Aguiar Campanini (Lulu), pela atenção e carinho com que trata todas as pessoas e, em especial, por esses anos que me tratou como sua filha. Ao Denny Marcos Garcia, agradeço imensamente por toda contribuição e paciência, pois este trabalho não seria concluído sem sua ajuda e à Lucia Dantas Giglio, pela prontidão nos momentos de dúvida e pelo convívio diário, tornando o dia a dia mais leve.

À Maria Cecília Onofre, pela atenção e paciência durante meu percurso.

À CAPES, pelo suporte financeiro para a realização desta pesquisa.

Aos pacientes e voluntários que participaram desta pesquisa, que dispuseram de seu tempo, fico imensamente agradecida pela colaboração e confiança.

E a todos que indiretamente colaboraram para a realização desse trabalho. 
"Que o Senhor nos dê esta graça. A graça de rezar diante de Deus com liberdade, como filhos; de rezar com insistência, de rezar com paciência. Mas, sobretudo, rezar sabendo que eu falo com meu Pai, e meu Pai me ouvirá."

Papa Francisco

E Ele me ouviu... 


\section{RESUMO}

Vilela, M. Desempenho da mímica facial e qualidade de vida na fase aguda da paralisia facial periférica [dissertação]. Ribeirão Preto: Universidade de São Paulo, Faculdade de Medicina de Ribeirão Preto; 2019.

Introdução: A paralisia facial periférica (PFP) é a neuropatia craniana mais comum, o qual o nervo facial, responsável pela mímica facial, perde sua função. Com isso, entende-se a importância de se investigar o impacto psicológico que ela causa nos portadores desta patologia e os prejuízos quanto à função muscular, para auxiliar no diagnóstico e prognóstico. Objetivos: Analisar o desempenho da mímica facial na PFP comparativamente a sujeitos controles e suas relações com a qualidade de vida (QV) e a gravidade de comprometimento motor. Métodos: Trata-se de um estudo observacional transversal em que foram selecionados pacientes com PFP unilateral adquirida em fase aguda, entre 18 e 59 anos (GPFP) e sujeitos controles (GC) na mesma faixa etária. Um total de 236 sujeitos com paralisia facial foram triados e, destes, 35 sujeitos com paralisia de Bell compuseram o GPFP, com idade média de 34,2 anos $( \pm 13,6)$ e 28 sujeitos o GC com idade média 33,9 anos $( \pm 13,1)$. Os pacientes com PFP foram classificados segundo o grau de comprometimento motor de House e Brackmann. Investigou-se o Índice de Incapacidade Facial - IIF (físico e social), relacionado à QV, a Avaliação da Mobilidade da Mímica Facial (AMMF) e a Análise Tridimensional (3D) do Movimento Facial. Adotou-se o teste não paramétrico de Mann Whitney na comparação entre os grupos para o questionário de IIF, AMMF e análise 3D. O teste de correlação de Spearman analisou as relações entre o grau da PFP e as demais variáveis. Resultados: Com relação ao IIF, o GPFP possui escores significantemente menores em relação ao GC para ambos subíndices: físico $(P<0,0001)$ e social $(P<0,0141)$. As mulheres com PFP parecem sofrer mais no âmbito social que os homens $(P=0,046)$. Os valores globais de mímica facial gerados pelo AMMF também se mostraram menores no GPFP comparados ao GC $(P<0,0001)$, assim como na comparação individual de cada músculo $(\mathrm{P}<0,0001)$. A análise 3D mostrou índices de assimetria significantemente 
maiores no GPFP $(P<0,0001)$. Houve correlação entre o grau da PFP e QV para função física $(\rho=-0,40 ; P<0,01)$; entre 0 aumento da idade com a piora da QV para função física $(\rho=-0,45 ; P<0,005)$. A AMMF mostrou correlação com o grau $(\rho=-0,65 ; P<0,0001)$ e com a QV para função física $(\rho=0,56 ; P=0,0004)$. Com relação à análise $3 \mathrm{D}$, todas as provas de mímica facial pesquisadas se correlacionaram com o grau da PFP, com exceção da prova de protrusão labial e se correlacionaram com a QV as provas de surpresa, sorriso aberto e sorriso fechado. Conclusões: Pacientes com PFP possuem um déficit na função muscular quando comparados aos controles com relação à capacidade facial relacionada à $\mathrm{QV}$, à mímica facial e diferenças de assimetria facial, sendo as mulheres que sofrem mais no âmbito social em relação à QV. A capacidade física relacionada à $\mathrm{QV}$ foi influenciada pela gravidade da PFP, pelo aumento da idade, pela piora no desempenho da mímica facial e pela análise 3D em três provas de mímica facial. A piora da PFP influenciou no desempenho muscular e na análise 3D do movimento facial.

Palavras-chave: 1. Paralisia facial. 2. Qualidade de vida. 3. Assimetria facial. 4. Expressão facial. 5. Paralisia de Bell. 
Vilela, M. Facial mimicry performance and quality of life in the acute phase of peripheral facial paralysis [dissertacion]. Ribeirão Preto: University of São Paulo, School of Medicine of Ribeirão Preto; 2019.

Introduction: Peripheral facial paralysis (PFP) is the most common cranial neuropathy, which the facial nerve responsible for facial mime loses its function. Therefore, it is understood the importance of investigating the psychological impact that it causes in the patients of this pathology and the damages regarding the muscular function to aid in the diagnosis and prognosis. Objectives: To analyze the performance of facial mimicry in PFP compared to healthy control subjects and their relation with quality of life (QOL) and severity of motor impairment. Methods: This research was a cross-sectional observational study in which patients with unilateral acquired PFP in the acute phase, between 18 and 59 years old (GPFP) and healthy control subjects (CG) at the same age group. A total of 236 subjects with facial paralysis were screened, and of these, 35 subjects with Bell's palsy comprised the GPFP, the mean age was 34.2 years $( \pm 13.6)$ and 28 subjects with $G C$ with a mean age of 33.9 years $( \pm 13.1)$. Patients with PFP were classified according to the degree of motor engagement of House and Brackmann. The Facial Disability Index FDI (physical and social), related to QOL, the Facial Mimicry Mobility Assessment (FMMA) and the Three-Dimensional Analysis (3D) of the Facial Movement were investigated. The non-parametric Mann Whitney test was used in the comparison between the groups for the FDI, FMMA and 3D analysis. Spearman's correlation test analyzed the relationship between the PFP grade and the other variables. Results: Regarding FDI, the GPFP has significantly lower scores than the $C G$ for both subscripts: physical $(P<0,0001)$ and social $(P<0,0141)$. Women with PFP appear to suffer more socially than men $(P=$ $0,046)$. The overall values of facial mimicry generated by the FMMA were also lower in the GPFP compared to the CG $(P<0,0001)$, as well as in the individual comparison of each muscle $(P<0,0001)$. The $3 D$ analysis showed significantly higher asymmetry indexes in GPFP $(P<0,0001)$. There was a correlation 
between the degree of PFP and QOL for physical ( $\rho=-0,40, P<0,01)$; between the increase in age and worsening of $Q O L$ for physical $(\rho=-0,45, P<0,005)$. The FMMA showed correlation with the degree $(\rho=-0,65, P<0,0001)$ and with the $\mathrm{QOL}$ for physical $(\rho=0,56, P=0,0004)$. Regarding the $3 \mathrm{D}$ analysis, all the facial mimicry tests searched correlated with the degree of the PFP, except for the lip protrusion test and the tests of surprise, open smile and closed smile were correlated with the QOL. Conclusions: Patients with PFP have a deficit in muscle function when compared to healthy control group in relation to facial capacity related to QOL, facial mimicry and facial asymmetry differences, with women suffering more in the social context in relation to QOL. The physical capacity related to QOL was influenced by PFP severity, age increase, worsening of facial mimicry performance and $3 \mathrm{D}$ analysis in three facial mimicry tests. Worsening of PFP influenced muscle performance and 3D analysis of facial movement.

Keywords: 1. Facial paralysis. 2. Quality of life. 3. Facial asymmetry. 4. Facial expression. 5. Bell's palsy. 


\section{LISTA DE FIGURAS}

Figura 1. Fluxograma da composição do grupo paralisia facial periférica.. $\quad 38$

Figura 2. Fluxograma da composição do grupo controle......................... $\quad 39$

Figura 3. Tempo de acometimento pela PFP..................................... $\quad 42$

Figura 4. Voluntário posicionado em frente às oito câmeras de vídeo...... 47

Figura 5. Pontos antropométricos de tecido mole facial utilizados, segundo Farkas (1994) e adaptações.................................................. 50

Figura 6. Repouso, movimentos de mímica e as coordenadas correspondentes. A. Repouso; B. Cara de surpresa; C. Cara de raiva; D. Cara de cheiro ruim; E. Sorriso aberto; F. Sorriso fechado; G. Protrusão labial. 


\section{LISTA DE QUADROS}

Quadro 1. Descrição dos graus e suas características segundo House e Brackmann (1985)

Quadro 2. Graduação da mobilidade da musculatura facial segundo a classificação de Fouquet (2000) adaptado da proposta de avaliação de Chevalier et al (1987).

Quadro 3. Músculo ou grupo muscular e o comando dado pela avaliadora

Quadro 4. Descrição dos pontos antropométricos de tecido mole facial utilizados segundo Farkas (1994) e algumas adaptações

Quadro 5. Pontos antropométricos, prova de mímica e seu eixo correspondente. 


\section{LISTA DE TABELAS}

Tabela 1. Distribuição dos grupos controle (GC) e paralisia facial periférica (GPFP) quanto ao sexo e idade

Tabela 2. Distribuição quanto ao grau de paralisia facial segundo a escala de classificação para o grupo paralisia facial periférica (GPFP).......

Tabela 3. Mediana, média e desvio padrão do Índice de Incapacidade Facial referente à QV e diferença entre o grupo controle (GC) e paralisia facial periférica (GPFP)

Tabela 4. Diferença entre os sexos pelo Índice de Incapacidade Facial (IIF) referente à qualidade de vida $(\mathrm{QV})$ dos grupos controle $(\mathrm{GC})$ e paralisia facial periférica (GPFP)

Tabela 5. Mediana, média e desvio padrão na Avaliação da Mobilidade da Mímica Facial (AMMF) e diferença entre os grupos controle (GC) e paralisia facial periférica (GPFP) para cada grupo muscular avaliado e escore total

Tabela 6. Valores entre os lados da face e sua razão, na comparação entre os grupos controle (GC) e paralisia facial periférica (GPFP) para as seis provas de mímica facial

Tabela 7. Correlação entre o grau da paralisia facial segundo a escala de comprometimento motor de House-Brackmann (1985) e o Índice de Incapacidade Facial (IIF) referente à qualidade de vida (QV)

Tabela 8. entre idade e o Índice de Incapacidade Facial (IIF) referente à qualidade de vida $(\mathrm{QV})$ para os grupos controle $(\mathrm{GC})$ e paralisia facial periférica (GPFP)

Tabela 9. Correlação entre a Avaliação da Mobilidade da Mímica Facial (AMMF) com o Índice de Incapacidade Facial (IIF) referente à qualidade de vida (QV) e o grau da paralisia facial segundo a escala de comprometimento motor de House-Brackmann (1985).

Tabela 10. Correlação entre o Índice de Incapacidade Facial (IIF) referente à qualidade de vida $(\mathrm{QV})$, grau de comprometimento motor e as expressões faciais em seus eixos e relação tridimensional (3D). 


\section{LISTA DE SIGLAS E ABREVIATURAS}

$\begin{array}{ll}\text { 2D } & \text { Bidimensional } \\ \text { 3D } & \text { Tridimensional } \\ \text { AMMF } & \text { Avaliação da mobilidade da mímica facial } \\ \text { CEOF } & \text { Centro Especializado de Otorrinolaringologia e Fonoaudiologia } \\ \text { FMRP } & \text { Faculdade de Medicina de Ribeirão Preto } \\ \text { GC } & \text { Grupo controle } \\ \text { GPFP } & \text { Grupo paralisia facial periférica } \\ \text { HCFMRP } & \text { Hospital das Clínicas da Faculdade de Medicina de Ribeirão } \\ & \text { Preto } \\ \text { IIF } & \text { Índice de incapacidade facial } \\ \text { LISE } & \text { Laboratório de Investigação do Sistema Estomatognático } \\ \text { LNP } & \text { Lado não paralisado } \\ \text { LP } & \text { Lado paralisado } \\ \text { NAP-CF } & \text { Núcleo de Apoio à Pesquisa em Morfofisiologia Craniofacial } \\ \text { NF } & \text { Nervo facial } \\ \text { PB } & \text { Paralisia de Bell } \\ \text { PFC } & \text { Paralisia facial central } \\ \text { PFP } & \text { Paralisia facial periférica } \\ \text { QV } & \text { Qualidade de vida } \\ \text { USP } & \text { Universidade de São Paulo }\end{array}$

Condições experimentais

$\begin{array}{ll}\text { CR } & \text { Cheiro ruim } \\ \text { PT } & \text { Protrusão labial } \\ \text { RV } & \text { Raiva } \\ \text { SA } & \text { Sorriso aberto } \\ \text { SF } & \text { Sorriso fechado } \\ \text { SP } & \text { Surpresa }\end{array}$




\section{SUMÁRIO}

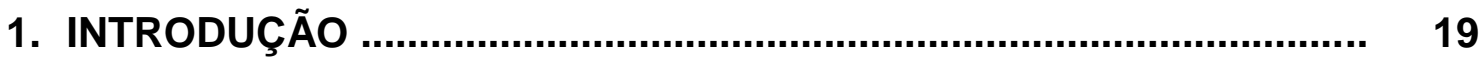

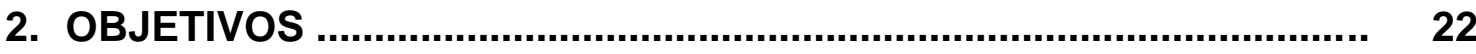

3. REVISÃO DE LITERATURA …...................................................... 24

3.1. Paralisia facial periférica ……………….......................... 24

3.1.1. Paralisia facial idiopática ..................................................... 26

3.2. Qualidade de Vida na Paralisia Facial Periférica ........................ 29

3.3. Análise Tridimensional do Movimento Facial............................. 31

4. MATERIAIS E MÉTODOS …....................................................... 36

4.1. Considerações éticas ………............................................ 36

4.2. Casuística ....................................................................... 36

4.3. Critérios de inclusão e exclusão …………………………..... 39

4.4. Procedimentos ................................................................ 42

4.5. Análise estatística ............................................................... 54

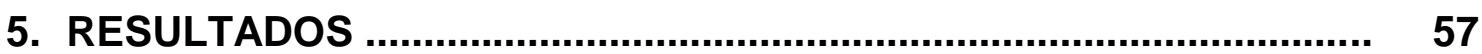

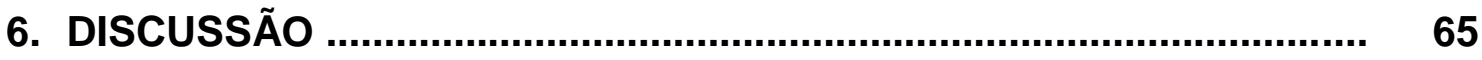

7. CONCLUSÕES …....................................................................... 76

8. REFERÊNCIAS BIBLIOGRÁFICAS ................................................ 78

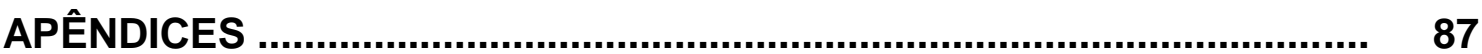

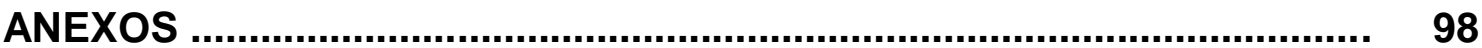


1. INTRODUÇÃO 


\section{INTRODUÇÃO}

Em uma sociedade em que os padrões estéticos são supervalorizados, a face representa um dos mais importantes meios de inserção social (Santos, 2006). Além disso, a face é responsável por transmitir ideias e emoções por meio da expressão facial, como um mecanismo sofisticado (Santos, 2006; Frith, 2009). Um prejuízo nesta importante ferramenta de comunicação social afeta tanto o autoconceito de uma pessoa quanto o julgamento dos observadores (Shaw, 1981).

A paralisia facial periférica (PFP) é a neuropatia craniana mais frequente originada por danos no nervo facial, responsável pela inervação dos músculos da mímica da face (Roob, Fazekas, Hartung, 1999). Na maioria dos casos, as investigações não estabelecem uma causa definida, por isso designam estes casos como etiologia idiopática (sendo esta de maior ocorrência), entre outras causas identificadas como traumática, infecciosa, tumoral, metabólica, congênita, vascular, neoplásica, iatrogênica, neurológica, sistêmica e tóxica (Miniti, Bento, Butugan, 2000; Mitre, Giancoli e Lazarini, 2006; Fonseca, 2018).

$A$ atuação médica na fase aguda da PFP é fundamental para se definir o diagnóstico etiológico, supor o prognóstico e estabelecer um plano de tratamento adequado para cada fase e evitar ou minimizar possíveis sequelas motoras. Quando a PFP é crônica tem-se um tratamento mais complexo, uma vez que as sequelas já podem estar estabelecidas e a reabilitação pode não ser tão satisfatória (Mitre, Giancoli, Lazarini, 2006).

Dentre as manifestações faciais da PFP, podemos destacar a assimetria facial, fraqueza muscular, dor facial e retroauricular, prejuízo no piscar, na proteção da córnea, na respiração nasal, na competência labial, na fala e no sorriso (Holland, Weiner, 2004; Owusu, Stewart, Boahene, 2018).

Investigações sobre a influência na qualidade de vida (QV) desses pacientes também deve ser valorizada (Kleiss et al., 2015; Nellis et al., 2016; Diaz-Aristizabal et al., 2017; Ordahan e Karahan, 2017), independentemente da escolha do tratamento, uma vez que há associação com depressão, isolamento social e redução da QV (Owusu, Stewart, Boahene, 2018). 
Nesse âmbito, o crescimento das pesquisas sobre os movimentos faciais contribui para o entendimento, a descrição e classificação da função facial (Sforza et al., 2010a). Estudos com tecnologia atual quantificaram os movimentos faciais tridimensionalmente, com maior precisão (Huffman et al., 1996; Salgado, Curtiss, Tollefson, 2010; Sforza et al., 2010a; 2010b; 2012a; 2012b; 2014; 2015; Frey et al., 2011; Sidequersky et al., 2016).

Para um adequado planejamento da reabilitação dos músculos da mímica facial, uma investigação detalhada é essencial e a avaliação clínica perceptiva visual é a ferramenta disponível que depende do treinamento e experiência do avaliador. Conhecer a capacidade de cada músculo individualmente, por meio da investigação clínica e por tecnologia tridimensional, trará a possibilidade de maximizar o processo terapêutico e enfatizar o que realmente encontra-se em defasagem.

Desse modo, propomos investigar o impacto da PFP em índices de incapacidades físicas e sociais relacionadas à face; no comportamento e desempenho muscular de forma global e individualizada para cada músculo ou grupo muscular e verificar os índices de assimetria facial de modo tridimensional, além de correlacionar estes resultados ao grau de comprometimento motor da PFP e à QV.

Nossa hipótese é a de que os portadores de PFP na fase aguda têm uma QV aquém dos sujeitos controles e apresentam um prejuízo na função muscular facial, que interfere nas expressões da face e prejudicam na interação social. Além disso, acreditamos que o grau da PFP pode interferir negativamente no desempenho dos músculos faciais e na QV. E, por fim, hipotetizamos que o grau da PFP pode influenciar algumas expressões faciais mais do que outras. Se confirmados, tais dados contribuirão e auxiliarão no direcionamento terapêutico em casos de PFP na fase aguda. 
2. OBJETIVOS 


\section{OBJETIVOS}

\section{Objetivos Gerais}

Analisar o desempenho da mímica facial na PFP unilateral adquirida, na fase aguda, comparativamente a sujeitos controles, e suas relações com a QV e com a gravidade de comprometimento motor.

\section{Objetivos Específicos}

Investigar a influência da PFP:

- em índices de incapacidade facial, físico e de bem-estar social, relacionados à QV e sua relação com o sexo;

- na mobilidade da mímica facial global e em provas isoladas pela análise perceptiva visual;

- na análise tridimensional optoeletrônica dos movimentos faciais durante a expressão de mímica facial e índices de assimetria;

Correlacionar as variáveis de QV com o grau de comprometimento motor, com a idade, com a mobilidade da mímica facial e com a análise tridimensional. A gravidade da PFP também será correlacionada ao desempenho da mímica facial e ao movimento tridimensional. 


\section{REVISÃO DE LITERATURA}

\subsection{Paralisia Facial Periférica (PFP)}

A PFP é caracterizada pela diminuição ou abolição da função do nervo facial (NF), VII par craniano, em seu segmento periférico de modo temporário ou não (Dib, Kosugi, Antunes, 2004).

O NF é responsável pela inervação dos músculos da mímica facial, com exceção daqueles inerentes à mastigação, que são inervados pelo nervo trigêmeo ( $V$ par craniano). Ele é um nervo misto, motor e sensitivo, no qual seus glânglios são derivados das cristas neurais. Possui aproximadamente 7000 mil fibras nervosas, no qual $58 \%$ são motoras, $24 \%$ pré-ganglionares para lacrimejamento e salivação e $18 \%$ são gustativas e outras sensitivas (Bento, Miniti, Marone, 1998; Miniti, Bento, Butugan, 2000).

Além de ser responsável pela mímica da face, ao NF são atribuídas funções fisiológicas importantes, como o lacrimejamento, a proteção do ouvido interno contra sons de alta intensidade, a sensibilidade gustativa e a salivação (Bento, Miniti, Marone, 1998).

A inervação motora do saco lacrimal e da pálpebra permite o lacrimejamento e a perda de tal função pode resultar em úlcera de córnea e consequente cegueira. A proteção do ouvido interno contra sons de alta intensidade, por sua vez, é realizada através do reflexo do músculo do estribo, inervado pelo ramo estapediano do NF. Quanto à sensibilidade gustativa, o VII par realiza tal função apenas nos 2/3 anteriores da língua por fibras aferentes, bem como a inervação motora por fibras eferentes das glândulas salivares submandibular e sublingual que são inervadas pelo nervo corda do tímpano, outro ramo do NF (Bento, Miniti, Marone, 1998; Miniti, Bento, Butugan, 2000).

A sensibilidade tátil das regiões do pescoço, pavilhão auricular (exceto héliz e lóbulo da orelha externa), pele do conduto auditivo externo e superfície externa da membrana do tímpano são inervadas pelo ramo cervical, envolvidos na libido humana e no movimento da boca que é de suma importância ao processo alimentar e na ingestão de líquidos (Bento, Miniti, Marone, 1998; Miniti, Bento, Butugan, 2000; Veiga, 2006). 
O suprimento arterial do NF é realizado pela artéria cerebelar ânteroinferior e pelas artérias petrosa e estilomastóidea e recebe também informações de várias estruturas encefálicas em seu complexo trajeto, desde sua origem no córtex até à chegada à musculatura (Bento, Miniti, Marone, 1998; Fernandes e Lazarini, 2006).

$\mathrm{Na}$ literatura, encontra-se a descrição anatômica do NF dividindo-o desde em três segmentos maiores (Fernandes e Lazarini, 2006) e em até em seis segmentos menores (Miniti, Bento, Butugan, 2000). Destes três segmentos maiores, destacam-se: supranuclear, nuclear e infranuclear.

No segmento supranuclear, os impulsos elétricos responsáveis pela motricidade dos músculos da face originam-se no córtex motor na região lateral e inferior ao córtex cerebral, região esta que representa a face. As informações do córtex motor percorrem o trato corticonuclear e o trato corticoespinal em direção ao tronco cerebral e antes de chegar ao núcleo facial as fibras dividem-se para que uma parte do feixe de fibras corticonuclear cruze a linha média e caminhe em direção ao núcleo facial contralateral, enquanto a outra parte permaneça no lado ipsilateral (Fernandes e Lazarini, 2006).

O segmento nuclear é o mais desenvolvido entre os núcleos motores do tronco cerebral. Localiza-se à frente do núcleo ambíguo, medial ao trato espinal do trigêmeo e lateral ao fascículo longitudinal medial. Possui aproximadamente quatro milímetros de comprimento e de 7 a 10,5 mil células nervosas, o que justifica a grande flexibilidade da musculatura da face e seu excepcional desempenho, com movimentos delicados e precisos (Lazarini, Mitre, Szajubok, 2002; Fernandes e Lazarini, 2006).

Enquanto que o segmento infranuclear posiciona-se na porção ventrolateral do sulco bulbopontino é circundado pela aracnoide até a entrada no canal do NF, onde está prolongado pela dura-máter, formando o epineuro, até atingir o forame estilomastóideo. Em seu trajeto, a partir do tronco cerebral, o NF é dividido em segmentos anatômicos: pontino, meatal, labiríntico, timpânico, mastóideo e extracraniano (Fernandes e Lazarini, 2006). 
Esses três segmentos podem ser afetados com comprometimentos distintos. Nas lesões nucleares e infranucleares a paralisia facial se manifesta em todos os terços faciais. No entanto, as lesões na região supranuclear acometem os músculos inferiores da face, podendo ainda envolver outras regiões, como língua, dedos e mãos (Lazarini, Mitre, Szajubok, 2002). Quando a paralisia facial for central (PFC), há a ocorrência de lesões supranucleares situadas na via exclusivamente motora do NF, abrangendo a área motora cortical cerebral até o núcleo do NF, localizado na ponte do tronco encefálico. Geralmente, a PFC é acompanhada de hemiparesia do lado contralateral à lesão cerebral e por apenas a motricidade da mímica facial do terço inferior estar afetado, pode-se ocasionar discreta disartria, devido à dificuldade do músculo orbicular da boca em articular os fonemas labiais e dentolabiais (Veiga, 2006).

Pode ainda ocorrer casos de PFP bilateral, no entanto esses casos são raros, cerca de $0,3 \%$ (Vakharia e Vakharia, 2016) e geralmente são decorrente de síndromes, como Síndrome de Lyme, Melkerson-Rosenthal e Sequência de Möebius (Caropreso, 2000).

\subsubsection{Paralisia facial idiopática}

Considerada idiopática, a paralisia de Bell é a causa mais comum de paralisia aguda unilateral do NF. O cirurgião escocês Sir Charles Bell é frequentemente associado à PFP de causa idiopática e deve-se ao fato de que em 1821 ele foi o primeiro a observar que tal condição ocorria devido ao envolvimento do VII par craniano, através de estudos clínicos e experimentais (Reich, 2017), e após oito anos, Bell apresentou três casos de disfunção nervosa, no qual dois eram de causa idiopática, determinando assim, que o VII controlava os músculos da expressão facial. Por este motivo, os casos de paralisia facial idiopáticos são denominados de paralisia da Bell (PB) (McCaul et al., 2014).

No entanto, a reativação da infecção pelo vírus herpes latente no gânglio geniculado é a principal causa suspeita (Schirm, Mulkens, 1997) com hipótese de uma associação entre determinadas condições climáticas e o risco de PB 
(Franzke et al., 2018), que resulta em edema e inflamação dentro do canal de Falópio, canal ósseo e rígido, que comprometerá a vascularização do nervo ao longo do segmento labiríntico e por consequência, a degeneração nervosa e alterações secundárias no núcleo facial (Owusu, Stewart, Boahene, 2018). Além disso, alguns autores sugerem uma variação anatômica no diâmetro do NF e redução no diâmetro do canal do NF, o que poderia explicar a paralisia diante de uma afecção viral em algumas pessoas e em outras não (Vianna et al., 2014).

O sintoma mais evidente na PB é a paresia de início súbito e evolução rápida, com fraqueza muscular após dois dias. Hiperacusia, hipolacrimejamento e disgeusia são associados, além de otalgia, plenitude aural, dor facial e retroauricular que podem preceder a paralisia (Holland, Weiner, 2004). Ela ainda causa uma incapacidade oral temporária significativa e incompetência no fechamento da pálpebra, o que leva a possíveis lesões oculares (Owusu, Stewart, Boahene, 2018).

Uma avaliação abrangente da paralisia facial incluirá o histórico e exame físico para determinar a causa, extensão, comprometimento, a fim de se determinar o início, a progressão, os sintomas associados, fatores de risco, e a exposição a vários vírus, sintomas de estresse e resfriado, além da avaliação dos ramos do NF e demais nervos, palpação em glândula parótida, observação em repouso e ao movimento voluntário da mímica facial (Zhao, Feng, Gao, 2015; Owusu, Stewart, Boahene, 2018). A utilização de escalas para mensurar o grau de comprometimento da paralisia facial se faz presente na prática clínica (Fonseca et al., 2015), como a escala de House e Brackamann (1985), que apesar de apresentar críticas, foi adotada pelo Comitê de Distúrbios do Nervo Facial como padrão-ouro para avaliação e a mais aceita pela literatura (Berg, Jonsson, Engström, 2004). Além disso, há a possibilidade de testes eletrofisiológicos como o teste de excitabilidade do NF e teste de estimulação máxima, mas estes são testes subjetivos, ao passo que a eletroneuromiografia e eletromiografia possuem caráter objetivo (Zhao, Feng, Gao, 2015). Avaliar o limiar auditivo que normalmente não é afetado na $\mathrm{PB}$, também se faz necessário, pois os reflexos do estapédio podem estar reduzidos ou ausentes (Holland, Weiner, 2004). 
A PB possui uma incidência de 20 a 40 casos por 100.000/ano, em que $60 \%$ a $75 \%$ dos casos de PFP são caracterizados por início repentino sem causa aparente (Reich, 2017; Atolini Junior et al., 2009). Além disso, mulheres grávidas têm cerca de 3,3 vezes mais chances de ter PB quando comparadas a mulheres não grávidas na mesma faixa etária (Hilsinger, Adour, Doty, 1975), provavelmente devido a um edema tecidual generalizado na gravidez, que causa compressão mecânica do NF no canal das trompas (Gillman et al., 2002). Diabéticos também possuem maior risco para $\mathrm{PB}$, ao que sugere ser resultante de uma isquemia do NF devido à doença diabética de pequenos vasos (Pecket, Schattner, 1982).

Quanto ao prognóstico da PB, há recuperação completa em cerca de $80 \%$ dos casos, no entanto, $15 \%$ permanecem com algum tipo de dano ao nervo e $5 \%$ apresentam sequelas severas (Finsterer, 2008), incluindo fraqueza facial moderada a severa, sincinesia ou contratura muscular, além de relatos de dor facial em alguns casos (Holland, Weiner, 2004).

A ocorrência de um novo episódio de PFP, nos casos de PB, varia de 0,8 a 19,4\% sem diferença entre os sexos (Dong et al., 2019), no qual adultos e crianças têm as mesmas chances para novos quadros (Cirpaciu, Goanta e Cirpaciu, 2014).

A interrupção da via neuromuscular do córtex motor facial até os músculos faciais é o achado mais comum às diversas causas de paralisia facial e o nível em que ocorre a interrupção patológica e o distúrbio funcional consequente determinará o melhor tratamento. Recuperar o tônus facial e a mímica facial paralisada requer a restauração da rede de músculos nervosos interrompida, seja pela regeneração espontânea do NF ou pelo reparo cirúrgico dos nervos ou músculos comprometidos (Owusu, Stewart, Boahene, 2018).

Dentre os tratamentos conservadores propostos, estão a combinação de antiviral e esteróide, com melhora significante na recuperação geral comparada a terapia individual de cada um dos medicamentos (Fu et al., 2018), sendo este mais eficaz antes de 72 horas e menos eficaz após sete dias. Cuidados com os olhos a fim de proteger a córnea da secagem e abrasão, com colírios lubrificantes e pomadas à noite são necessários (Holland, Weiner, 2004). Massagem e exercícios faciais são recomendados aos pacientes. Algumas 
evidências apóiam a terapia da mímica facial por meio de biofeedback com espelhos e eletromiografia (Beurskens, Heymans, 2003; Beurskens, Heymans, 2006; Pereira et al., 2011), bem como a utilização de acupuntura para a reabilitação destes pacientes (Zhao, Feng, Gao, 2015). No entanto, há poucos ensaios clínicos controlados sobre a eficácia destas terapias para recuperação da paralisia facial. A intervenção cirúrgica é utilizada para a descompressão do NF (Fisch, 1981), porém pode acarretar riscos, como convulsões, surdez, vazamento de líquido cefalorraquidiano e lesão ao nervo (Holland, Weiner, 2004).

\subsection{Qualidade de Vida na Paralisia Facial Periférica}

Quando se fala dos aspectos envolvidos nos cuidados com a PFP, levamos em consideração o manejo com a anamnese, avaliação e os tratamentos específicos, cirúrgicos ou não, porém é necessária uma atenção especial às questões psíquicas envolvidos na doença em questão. A avaliação do grau da PF é realizada com escalas de graduação, no entanto, apesar de descreverem a severidade da paralisia, estas escalas não avaliam como a doença afeta a QV do paciente (Fonseca, 2018). Portanto, para se investigar a QV desses sujeitos, dois questionários são os mais utilizados na literatura: 0 FaCE Score e o Facial Disability Index (Ho et al., 2012; Fonseca, 2018).

O questionário FaCE Score é um instrumento de QV validado na língua inglesa por Kahn et al. (2001) com capacidade de medir de forma precisa e confiável a deficiência e o comprometimento facial após a paralisia facial. Possui 15 questões, cada uma usando uma escala tipo Likert de cinco itens, no qual o próprio indivíduo a completa. A resposta que o indivíduo julga mais apropriada deverá ser circulada em cada declaração, sendo que 1 corresponde à função mais baixa e 5 corresponde à função mais alta. As afirmações são posteriormente agrupadas em seis domínios independentes: função social, movimento facial, conforto facial, função oral, conforto dos olhos e controle lacrimal. Uma nota geral agrupa todos esses domínios e utilizando-se uma fórmula específica, calcula-se a pontuação do indivíduo, no qual zero corresponde a pior pontuação e 100 a melhor. O questionário FaCE Score foi 
validado formalmente e demonstrou excelente consistência interna, bem como confiabilidade em teste e reteste.

O questionário Facial Disability Index ou Índice de Incapacidade Facial (IIF) validado por VanSwearingen e Brach (1996) foi traduzido e adaptado por Toledo (2007). É um questionário de autoavaliação de distúrbios do NF, que considera a experiência pessoal de cada paciente e quantifica as condições físicas e psicossociais relacionadas à musculatura facial. Dividido em duas partes, avalia-se o índice de função física, com cinco questões abrangendo dificuldades nas funções estomatognáticas, como mastigação, deglutição e fala, além de desconforto na condição ocular e higiene oral. A segunda parte do questionário investiga por meio de cinco questões o índice de bem estar social. Para cada subíndice, o escore zero corresponde a pior QV e o escore 100 a melhor.

O estudo de Toledo (2007) investigou a QV, por meio do IIF, em sujeitos com paralisia facial crônica, pré e pós terapia miofuncional orofacial e uso de toxina botulínica. A autora observou diferenças nos valores de QV para ambos subíndices apenas para o grupo que utilizou a toxina botulínica após a intervenção de terapia miofuncional orofacial.

Embora esses questionários de QV, aplicados em casos de paralisia/disfunção do NF, mostrem evidências de desenvolvimento e validação, nenhum deles contempla todas as diretrizes (Ho et al., 2012). No entanto, mesmo diante de algumas limitações, são os instrumentos que mais contemplam a doença em questão.

A associação entre o aumento de depressão e a menor QV foi evidenciada em pacientes com paralisia facial, comparados aos indivíduos controles, mesmo em questionário não específico para casos de paralisia facial. Desse modo, há a necessidade de otimizar o cuidado e considerar o impacto psicológico nestes sujeitos (Nellis et al., 2016). Impactos e dificuldades já investigadas que vão além do prejuízo físico, e também se estendem a outros âmbitos como a incapacidade social e global, o que demonstrou correlações com a QV (Díaz-Aristizabal et al., 2017).

Há associação entre o aumento da idade com a menor QV em aspectos gerais nestes pacientes, e correlação entre o sexo feminino e o maior tempo de 
paralisia facial com uma menor QV em âmbitos sociais. Em uma avaliação clínica com pior função facial é provável que existam mais problemas psicossociais. Dessa forma, reforça-se a importância do aconselhamento psicológico para estes pacientes, principalmente em casos duradouros para melhorar sua disfunção psicossocial (Kleiss et al., 2015).

A incapacidade física e social investigada pelo questionário IIF mostrou-se melhor após o tratamento com toxina botulínica em casos crônicos, no qual refletiu uma melhora na QV desses pacientes após um longo período (Salles, Toledo e Ferreira, 2009; Nascimento Remigio et al., 2015). Há evidência de melhora na incapacidade facial e QV em seguimento pós-operatório de pacientes que foram submetidos à parotidectomia superficial verificados pelo questionário IIF quando comparados ao período prévio ao procedimento, com melhora constante ao longo dos meses (Prats-Golczer et al., 2017).

Além disso, a literatura mostrou eficácia na utilização da terapia a laser junto a exercícios de mímica facial em portadores de PFP verificados através dos valores demonstrados pelo IIF e progressiva melhora destes (Ordahan e Karahan, 2017).

A utilização de questionários para se entender as incapacidades e prejuízos na QV dessa população foi correlaciona às escalas de comprometimentos faciais de House e Brackmann (1985) e Sunnybrook (Ross, Fradet, Nedzelski, 1996), o que mostrou assertividade quando se investigou o impacto psicológico e, assim, forneceu embasamento para realmente humanizar 0 atendimento de pacientes com paralisia facial ( $\mathrm{Ng}$, Ngo, 2013; Kleiss et al., 2015; Prats-Golczer et al., 2017).

Os dois questionários são amplamente utilizados pela literatura internacional. Apesar de não serem validados no Brasil, o questionário IIF foi utilizado em diversos estudos brasileiros (Salles, Toledo e Ferreira, 2009; Sassi et al., 2011; Nascimento Remigio et al., 2015).

\subsection{Análise Tridimensional do Movimento Facial}

Até recentemente, a simetria facial era investigada utilizando-se principalmente técnicas de análise bidimensional (2D), no qual fotos eram 
examinadas e, na maioria dos casos, os marcos anatômicos na visão frontal eram determinados através de uma linha de referência (Berssenbrügge et al., 2014).

As tecnologias tridimensionais (3D) trouxeram para esse âmbito novos benefícios, pois são aplicadas para visualizar, quantificar e arquivar a expressão facial voluntária, em condições normais e patológicas (Verzé et al., 2011). A análise 3D fornece até $43 \%$ mais informações que a 2D, em que esta é menos apropriada para detectar diferenças da função facial, profundidade e forma (Gross, Trotman, Moffatt, 1996; Da Silveira et al., 2003).

De forma estática e dinâmica, as tecnologias empregadas para criar imagens em 3D e mensurar o movimento facial são variadas. Dentre elas, a varredura a laser, estereofotogrametria, sistemas fotográficos, digitalizadores de luz, digitalizador espacial, dispositivo optoeletrônico e tomografia computadorizada (Da Silveira et al., 2003), seja com o uso de marcadores reflexivos passivos, ativos ou sistemas sem marcadores (Popat et al., 2009).

De modo dinâmico, entre os vários instrumentos propostos, os analisadores de movimento optoeletrônicos, que utilizam marcadores reflexivos passivos, parecem ser os mais adequados para a coleta de dados, em pacientes e indivíduos saudáveis (Ferrario e Sforza, 2007). Dessa forma, os autores padronizaram animações máximas faciais para se quantificar o índice de simetria do movimento, como: sorriso máximo, sorriso espontâneo, elevação de testa com e sem a boca aberta, fechamento de olhos simultâneos e fechamento de olho direito e esquerdo. Para isso, foram utilizados 21 pontos antropométricos como marcadores de tecido mole na face. Também, outros movimentos faciais são utilizados para mensuração, como protrusão de lábios (Vimercati et al., 2012) e expressões faciais popularmente ditas como "medo", "prazer", "surpresa", "raiva", "tristeza" e "nojo" (Lee et al., 2015). Para avaliar os movimentos da fala, geralmente emprega-se palavras com sons bilabiais envolvendo articulação dos lábios superior e inferior (Popat et al., 2008a; 2008b; 2010; 2012) e sequências de vogais (Sidequersky et al., 2016).

O sistema optoeletrônico foi utilizado para a padronização dos movimentos faciais em adultos saudáveis, com relação ao sexo e idade e velocidade do movimento (Sawyer, See, Nduka, 2010; Sforza et al., 2010a, 
2010b; Giovanoli et al., 2003; Lowney et al., 2018) e na comparação entre homens e mulheres jovens saudáveis verificou-se que ambos possuem movimentos faciais simétricos e semelhantes, com alguma assimetria e assincronia individual, mesmo sendo saudáveis (Sforza et al., 2010a, 2010b; Vimercati et al., 2012; Sidequersky et al., 2014). Porém, há autores que ressaltam que os homens possuem movimentos mais amplos (Weeden, Trotman, Faraway, 2001; Giovanoli et al., 2003). Existem divergências na literatura em relação à influência da idade na simetria facial (Sforza et al., 2010b; Giovanoli et al., 2003).

Com relação à PFP, a análise quantitativa da sua gravidade poderá auxiliar na escolha da terapia e na definição do prognóstico (Katsumi et al., 2015), no entanto, a quantificação do movimento facial na PFP é encontrada na literatura de diferentes modos de mensuração (Johnson et al., 1994).

Quando se compara sujeitos controles aos sujeitos com paralisia facial unilateral pós parotidectomia conservadora, a análise tridimensional facial mostra movimentos menos amplos nos pacientes com paralisia facial, sendo 0 grau da paralisia um fator significativo (Sforza et al., 2012a). Além disso, pela análise de construção de imagem 3D, foi possível medir o movimento que a boca realiza na direção ântero-posterior, diferentemente da análise 2D, e correlacioná-las com escalas subjetivas de comprometimento motor com boa correlação entre si (Katsumi et al., 2015).

A análise do movimento 3D optoeletrônico também foi utilizada para avaliar a assimetria facial em pacientes com paralisia facial unilateral, pré e pós a reanimação do NF, com transferência para outros músculos, enxerto de nervos e a anastomose dos músculos massetérico-facial (Frey et al., 2008; 2011; Sforza et al., 2012b; 2015; 2014). O resultado para estas abordagens foi o mesmo: a melhora no movimento facial do lado paralisado, contribuindo para a melhora significativa na assimetria facial.

Portanto, a quantificação precisa da mímica facial, com base no sistema de captura de movimento, parece ser uma ferramenta pertinente para avaliar 0 desfecho de doenças faciais (Hontanilla e Auba, 2008).

De forma estática, utiliza-se para a análise 3D a varredura à laser da superfície facial, que é rápida e não invasiva e permite a visão em um espectro 
3D completo das características dos tecidos moles (Da Silveira et al., 2003; Verzé et al., 2011), além de alta precisão e exatidão quando comparadas com os métodos tradicionais, como o uso de paquímetro digital e fita (Fourie et al., 2011; Joe et al., 2012). Embora tenham baixo custo, são subjetivos, tem pouca repetibilidade e requerem o treinamento do avaliador para a medição ao vivo (Fourie et al., 2011; Verzé et al., 2011).

O método utiliza pontos antropométricos clássicos de referência (Farkas, 1994), e a superfície facial é reconstruída, por meio de um software, alinhado a varredura múltipla. Assim, com a análise dos pontos homólogos, permite-se quantificar a assimetria por meio do vetor de deslocamento 3D, expresso nos três planos espaciais (Ramieri et al., 2006; Verzé et al., 2011; Verzé et al., 2012).

O método foi utilizado para acompanhar um caso de paralisia facial pós cirúrgico de parotidectomia superficial e sua normalização foi progressiva conforme a recuperação clínica da mobilidade facial, considerando o deslocamento do marcador, amplitude e vetor. Houve recuperação completa da mobilidade facial, tanto na observação clínica como na varredura à laser (Verzé et al., 2011).

Recentemente, Sforza et al. (2018) utilizaram a estereofotogrametria para analisar os movimentos faciais tridimensionalmente em pacientes com PFP após reanimação facial, e os autores consideram o método inovador e de sucesso, além de servir como um treinamento progressivo durante o seguimento dos pacientes. 


\section{MATERIAIS E MÉTODOS}




\section{MATERIAIS E MÉTODOS}

\subsection{Considerações Éticas}

O presente trabalho foi realizado com apoio da Coordenação de Aperfeiçoamento de Pessoal de Nível Superior - Brasil (CAPES) - Código de Financiamento 001 e foi aprovado pelo Comitê de Ética em Pesquisa do Hospital das Clínicas da Faculdade de Medicina de Ribeirão Preto da Universidade de São Paulo (HCFMRP-USP) processo CAAE no 50892015.8.0000.5440 (ANEXOS A e B).

Os participantes do estudo foram devidamente esclarecidos sobre as condições que constam do documento "Esclarecimento do sujeito da pesquisa" e assinaram em concordância com o TERMO DE CONSENTIMENTO LIVRE E ESCLARECIDO (Apêndices A e B).

O presente estudo está de acordo com a Resolução no466, de 12 de Dezembro de 2012, do Conselho Nacional de Saúde.

Este estudo foi observacional transversal com início de coleta em setembro de 2016 e finalizado em janeiro de 2019 e faz parte do trabalho "Interrelações Morfofuncionais no Complexo Craniofacial", desenvolvido pelo Núcleo de Apoio à Pesquisa em Morfofisiologia Craniofacial da Universidade de São Paulo (NAPCF - USP).

\subsection{Casuística}

\section{Grupo Paralisia Facial Periférica}

Compôs a amostra do grupo paralisia facial periférica (GPFP) os sujeitos encaminhados para avaliação fonoaudiológica, no Setor de Fonoaudiologia do HCFMRP-USP após a consulta no setor de Otorrinolaringologia deste mesmo serviço com diagnóstico de paralisia facial, de ambos os sexos com idades entre 18 e 59 anos, sem distinção de raça e nível socioeconômico. O prontuário médico de cada voluntário foi consultado, na busca de informações referentes à confirmação de diagnóstico médico, informações sobre etiologia, tipo, grau de 
paralisia facial, procedimentos realizados e outras informações relevantes sobre a saúde geral do paciente.

Todos os pacientes que concordaram em participar deste estudo fizeram uso de Prednisolona $1 \mathrm{mg} / \mathrm{kg} / \mathrm{dia}$ e Aciclovir $30 \mathrm{mg} / \mathrm{kg} / \mathrm{dia}$ e para os cuidados oculares, utilizaram colírio Lacrime de 4 a 6 vezes/dia e pomada Epitezan ao dormir.

\section{Grupo Controle}

O grupo controle (GC) foi composto por voluntários saudáveis, recrutados aleatoriamente por meios de comunicação, como cartaz, telefonema e abordagem presencial sem histórico de PFP. Foram pareados quanto ao sexo e idade do GPFP e adotados os mesmos critérios acima.

Dessa forma, compôs o GPFP um total de 35 sujeitos, divididos em 15 mulheres e 20 homens, enquanto que o GC foi composto por 28 voluntários, com 12 mulheres e 16 homens. A distribuição dos grupos é apresentada na tabela 1 abaixo:

Tabela 1. Distribuição dos grupos controle (GC) e paralisia facial periférica (GPFP) quanto ao sexo e idade

\begin{tabular}{ccccc}
\hline & GC & Média (DP) & GPFP & Média (DP) \\
& $\mathbf{n}(\%)$ & anos & $\mathbf{n}(\%)$ & anos \\
\hline Mulheres & $12(42,9)$ & $34,2( \pm 13,6)$ & $15(42,9)$ & $34,6( \pm 15,2)$ \\
Homens & $16(57,1)$ & $33,7( \pm 13,1)$ & $20(57,1)$ & $33,8( \pm 12,6)$ \\
Total & 28 & $33,9( \pm 13,1)$ & 35 & $34,2( \pm 13,6)$
\end{tabular}

Sexo: Qui-Quadrado: $P=1,00$

Idade: Teste $t$ de Student: $\mathrm{P}=0,93$.

A casuística citada acima foi organizada de acordo com os fluxogramas apresentados nas Figuras 1 e 2, baseados nos critérios de inclusão e exclusão descritos a seguir. 
Figura 1. Fluxograma da composição do grupo paralisia facial periférica

\section{Recrutamento GPFP}

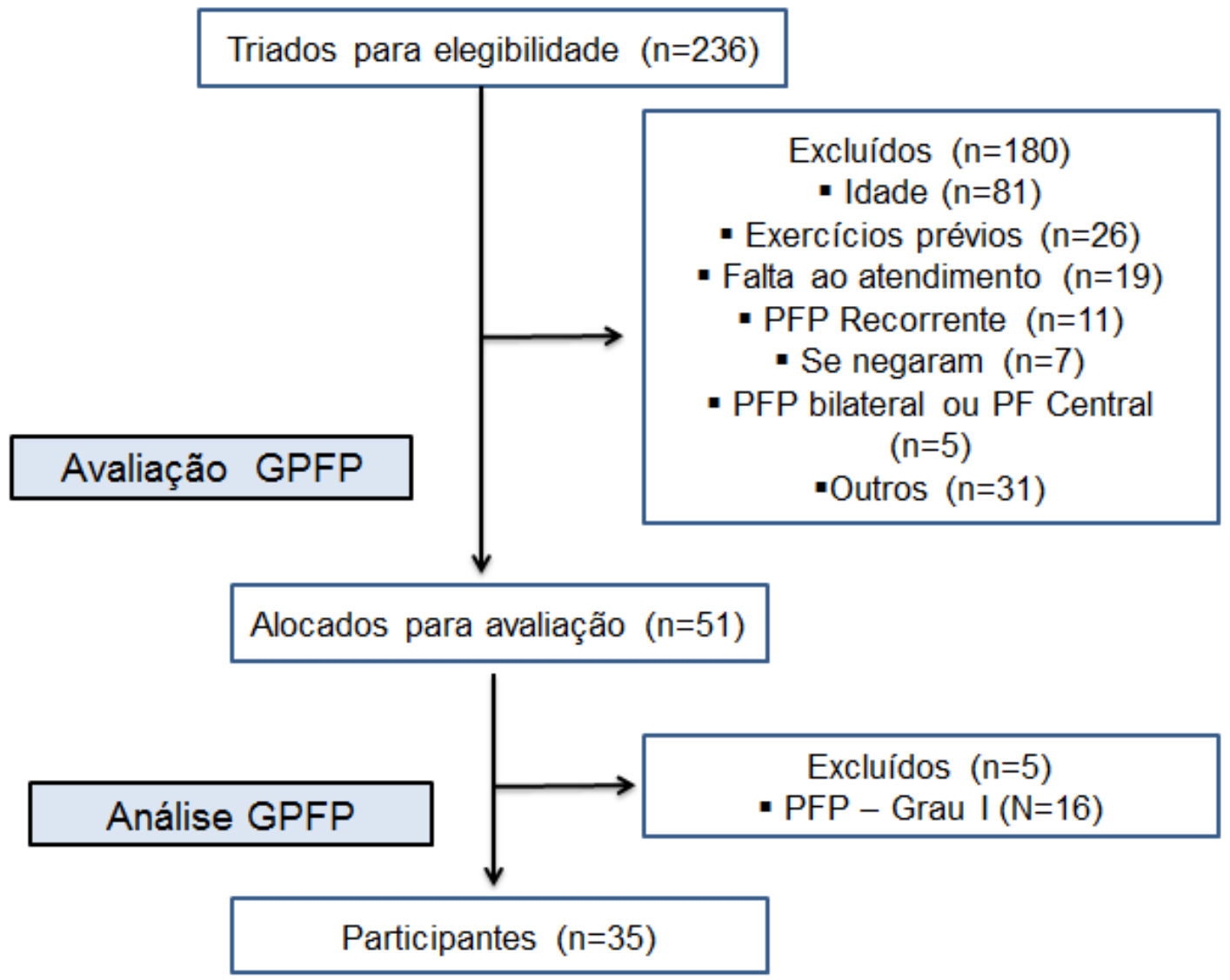

GPFP: grupo paralisia facial periférica. 
Figura 2. Fluxograma da composição do grupo controle

$$
\text { Recrutamento GC }
$$

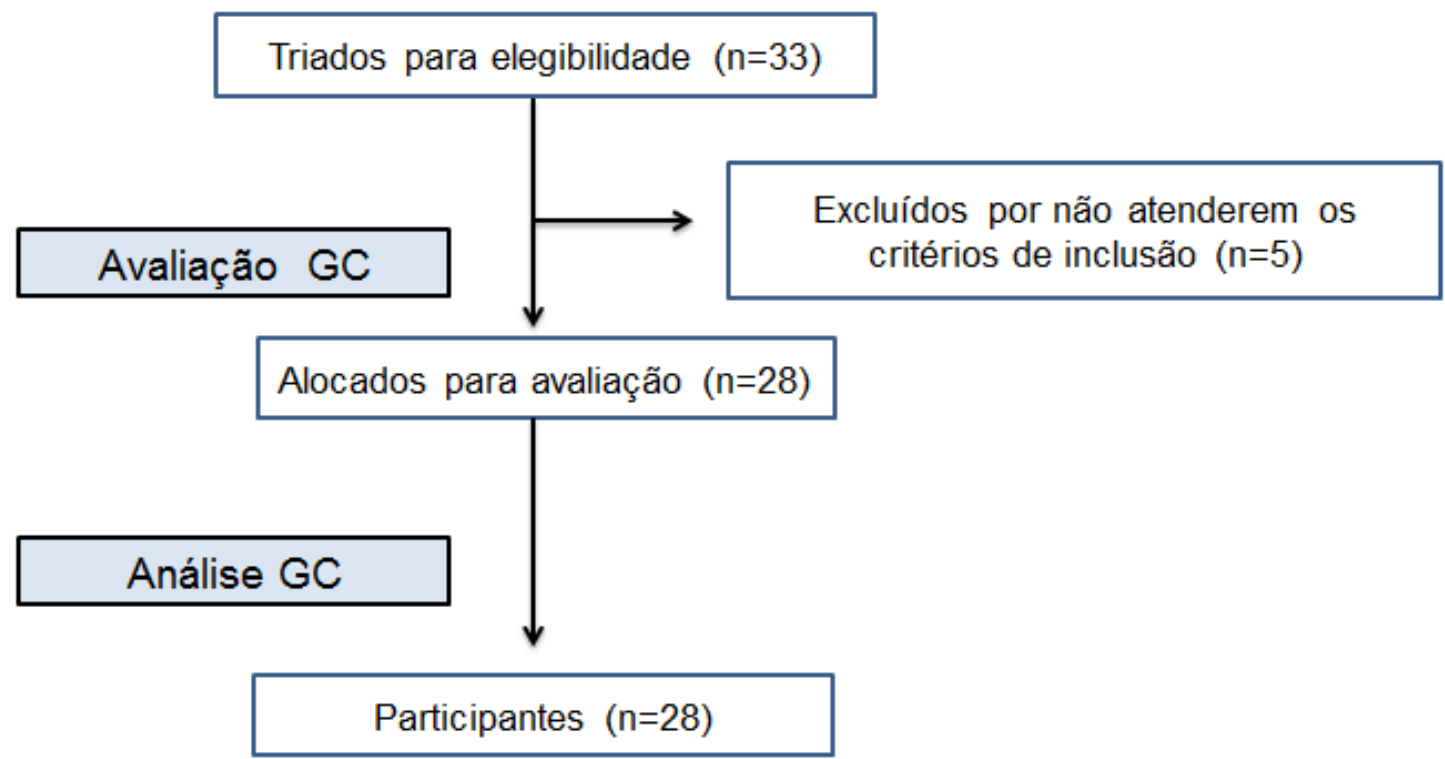

GC: grupo controle.

\subsection{Critérios de Inclusão e Exclusão}

Foram incluídos no GPFP os sujeitos com diagnóstico médico de PFP aguda com início do quadro em até três meses, de origem idiopática (Paralisia de Bell), com nacionalidade brasileira, sem distinção de raça e nível socioeconômico, encaminhados para avaliação fonoaudiológica, no Setor de Fonoaudiologia do HCFMRP-USP.

No GC foram incluídos os sujeitos de nacionalidade brasileira, saudáveis e sem histórico de PFP.

Como critério de exclusão não participaram do estudo para ambos os grupos os sujeitos que apresentassem síndromes genéticas, distúrbios cognitivos e/ ou mentais. Além disso, foram excluídos sujeitos usuários de prótese dentária total superior e inferior e portadores de outros distúrbios neuromusculares que não a PFP, no caso do GPFP. 
Para o GPFP, além dos critérios acima, foram excluídos os sujeitos que iniciaram qualquer tipo de intervenção terapêutica para a PFP com exceção ao tratamento medicamentoso previamente à avaliação e também os sujeitos que haviam passado por episódio de PFP prévio ao episódio atual.

No GC foram excluídos aqueles que estavam em tratamento ortodôntico, que tiveram trauma de face prévio e/ou fizeram procedimentos estéticos que envolvesse o uso de toxina botulínica.

A Escala de Classificação do Nervo Facial proposta por House e Brackmann (1985) foi utilizada para graduar o comprometimento motor. Ela é composta por seis graus de fácil aplicabilidade. O quadro 1 abaixo apresenta a descrição dos graus segundo suas características.

Quadro 1. Descrição dos graus e suas características segundo House e Brackmann (1985)

\begin{tabular}{|c|c|c|}
\hline Grau & Descrição & Características \\
\hline I & Normal & Função facial normal em todas as áreas \\
\hline II & $\begin{array}{l}\text { Disfunção } \\
\text { leve }\end{array}$ & $\begin{array}{l}\text { Fraqueza leve percebida por inspeção atenta; } \\
\text { Simetria em repouso } \\
\text { Testa com função moderada a boa } \\
\text { Olho com fechamento completo com mínimo } \\
\text { esforço } \\
\text { Sorriso ligeiramente assimétrico }\end{array}$ \\
\hline III & $\begin{array}{l}\text { Disfunção } \\
\text { moderada }\end{array}$ & $\begin{array}{l}\text { Paresia evidente, mas não desfigurante } \\
\text { Simetria em repouso } \\
\text { Testa com movimentação leve a moderada } \\
\text { Olho com fechamento completo com esforço } \\
\text { Boca levemente fraca ao esforço máximo } \\
\text { Pode haver espasmo, contratura e sincinesia, }\end{array}$ \\
\hline IV & $\begin{array}{l}\text { Disfunção } \\
\text { moderada/ } \\
\text { severa }\end{array}$ & $\begin{array}{l}\text { Paresia óbvia e/ou assimetria desfigurante } \\
\text { Simetria em repouso } \\
\text { Sem movimento de testa } \\
\text { Olho com fechamento incompleto }\end{array}$ \\
\hline
\end{tabular}




\begin{tabular}{|l|l|l|}
\hline & & Boca assimétrica ao esforço máximo \\
\hline $\mathrm{V}$ & Disfunção & Movimento pouco perceptível \\
& severa & $\begin{array}{l}\text { Assimetria em repouso } \\
\text { Sem movimento de testa } \\
\end{array}$ \\
& & $\begin{array}{l}\text { Olho com fechamento incompleto } \\
\text { Boca com leve movimento }\end{array}$ \\
\hline $\mathrm{VI}$ & Paralisia total & Sem nenhum movimento \\
\hline
\end{tabular}

Tendo em vista as recomendações adotadas pela Academia Americana de Otorrinolaringologia - Cirurgia de Cabeça e Pescoço, nós utilizamos esta escala para classificar os pacientes que compuseram esta pesquisa e sua distribuição pode ser visualizada na Tabela 2:

Tabela 2. Distribuição quanto ao grau de paralisia facial segundo a escala de classificação para o grupo paralisia facial periférica (GPFP)

\begin{tabular}{cc}
\hline $\begin{array}{c}\text { Escala de Classificação de } \\
\text { House e Brackmann (1985) }\end{array}$ & $\begin{array}{c}\text { Número de Sujeitos } \\
(\mathbf{n = 3 5 )}\end{array}$ \\
\hline Grau II & 4 \\
Grau III & 10 \\
Grau IV & 5 \\
Grau V & 15 \\
Grau VI & 1 \\
\hline
\end{tabular}

Com relação ao tempo transcorrido desde o início do quadro da paralisia facial até a data da avaliação, a figura 3 ilustra a distribuição em dias dos 35 sujeitos que compuseram a amostra. 
Figura 3. Tempo de acometimento pela PFP

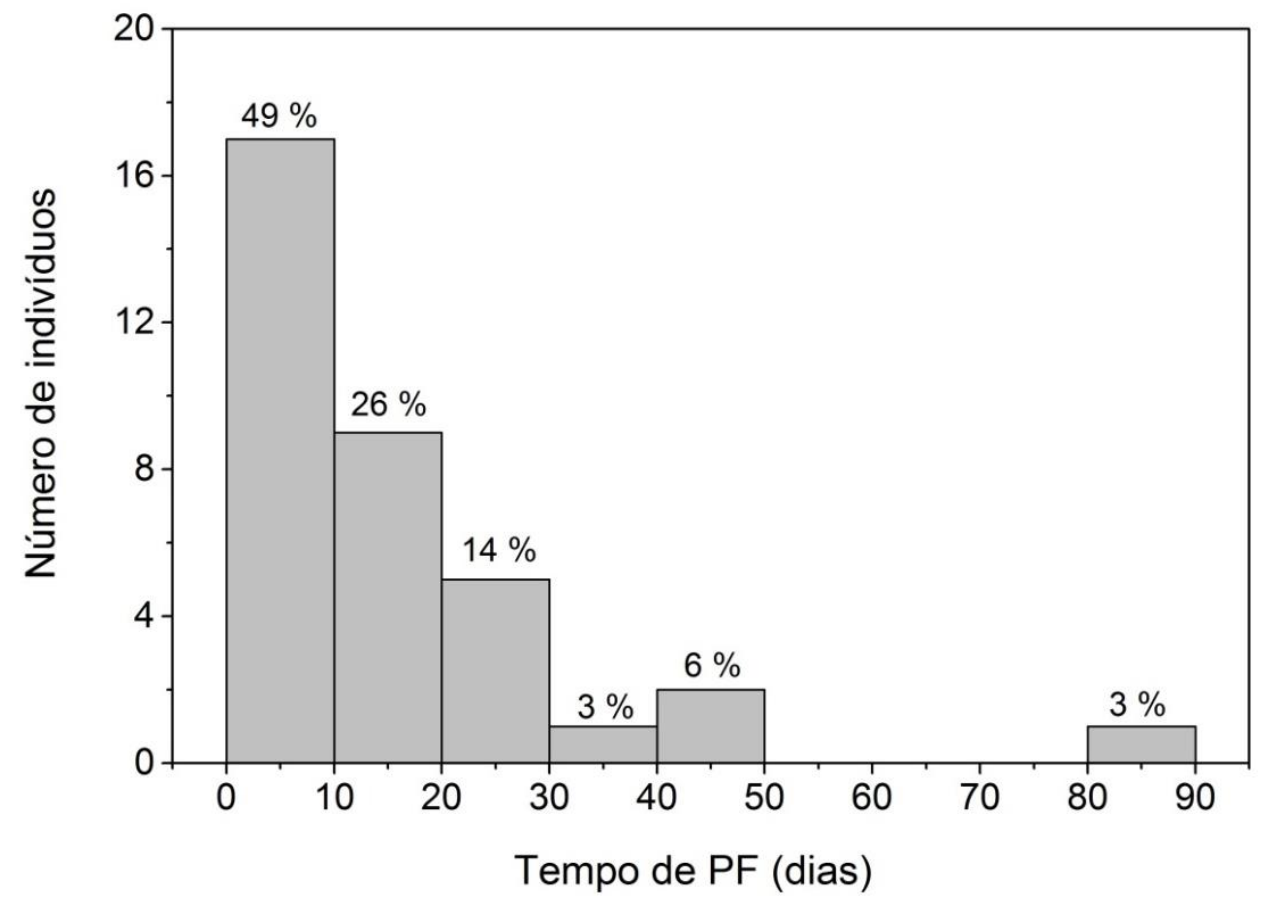

Todos os 236 indivíduos com paralisia facial triados para elegibilidade foram encaminhados para terapia miofuncional neste serviço, com exceção daqueles que faltaram ao atendimento e aqueles em que a paralisia facial havia se extinguido.

\subsection{Procedimentos}

Os procedimentos clínico e instrumental foram realizados no Laboratório de Investigação do Sistema Estomatognático (LISE) da Faculdade de Medicina de Ribeirão Preto da Universidade de São Paulo (FMRP-USP), localizados na Rua das Paineiras, casa 18, campus Ribeirão Preto - Universidade de São Paulo (USP), previamente agendados de acordo com a disponibilidade dos participantes. As avaliações e análises foram feitas por uma única fonoaudióloga com experiência de três anos em motricidade orofacial e previamente treinada em cada procedimento utilizado. Os procedimentos estão descritos a seguir: 


\subsubsection{Anamnese}

Após a seleção dos sujeitos e em acordo com o que foi assinado no termo de consentimento livre e esclarecido foi realizada uma anamnese a partir do Protocolo de Anamnese e Avaliação da Paralisia Facial (Fouquet, 2000) que constou de algumas perguntas dirigidas sobre identificação, início do quadro da paralisia facial, sintomas, queixas, providências tomadas, cirurgias realizadas e informações complementares como tipos de alterações, exames e tratamento realizados.

\subsection{2. Índice de Incapacidade Facial (IIF)}

O "Facial Disability Index" - Índice de Incapacidade Facial (IIF) (Van Swearingen, Brach; 1996) foi investigado por meio de um questionário, composto por duas partes :

- Parte I: Índice da Função Física

Composta por cinco questões (1 a 5) referentes às funções físicas como dificulfade em alimentar-se ou em beber líquidos. Cada pergunta deverá ser pontuada entre 1 e 5, onde (5) representa nenhuma dificuldade, (4) representa um pouco de dificuldade, (3) representa alguma dificuldade, (2) representa muita dificuldade. Há a opção ainda de não realizar a função, podendo-se classificar em (1) por razões de saúde e (0) por outros motivos. O Índice de Função Física será obtido subtraindo-se o escore total das questões de 1 a 5 pelo número de questões respondidas, dividindo-se esse valor novamente pelo número de questões respondidas. Esse valor obtido foi multiplicado por 25, segundo as autoras, para a obtenção o resultado final do Índice de Função Física;

\section{- Parte II: Índice de Bem-Estar Social}

Composta por cinco questões (6 a 10) referentes ao bem estar social, como participar de reuniões, sair para comer fora, ou sobre momentos de tranquilidade. As questões têm pontuações de 1 a 6 , onde (1) representa a todo o tempo, (2) a maior parte do tempo, (3) uma boa parte do tempo, (4) uma parte 
do tempo, (5) uma pequena parte do tempo, e (6) a nenhum momento. Com exceção da questão de número 6 , no qual a pontuação se inverte, e (6) representa a todo o tempo e (1) a nenhum momento. O Índice Bem-Estar Social é obtido subtraindo-se o escore total das questões de 6 a 10 pelo número de questões respondidas, dividindo-se esse valor novamente pelo número de questões respondidas. Esse valor obtido foi multiplicado por 20, para a obtenção do resultado final do Índice Bem-Estar Social.

Para ambas as partes, o escore máximo é de 100, o que indica o melhor estado físico e melhor bem estar social pesquisados.

\subsubsection{Avaliação da Mobilidade da Mímica Facial (AMMF)}

Uma investigação detalhada da mímica da face dos participantes foi realizada, por meio do Protocolo de Avaliação da Mobilidade da Mímica Facial (AMMF) (Fouquet, 2000) adaptado da proposta de avaliação de Chevalier et al (1987). Tal protocolo considera individualmente cada músculo da mímica facial. Sua aplicação ocorreu por meio de inspeção perceptiva visual realizada durante a avaliação e em seguida complementada pela análise de imagens registradas em vídeo, com a autorização dos participantes, para que pudessem ser confirmados os resultados duvidosos, no qual os indivíduos permaneceram sentados em uma cadeira com encosto, com a cabeça sem apoio e os pés apoiados no chão. Uma câmera filmadora (Sony® DCR-HC52 Digital) foi mantida no nível da face, pescoço e ombros do paciente por meio de um tripé durante a filmagem.

Para a avaliação da mobilidade da musculatura facial utilizou-se uma escala de cinco graus, apresentados no quadro 2 abaixo: 
Quadro 2. Graduação da mobilidade da musculatura facial segundo a classificação de Fouquet (2000) adaptado da proposta de avaliação de Chevalier et al (1987)

\begin{tabular}{|l|l|}
\hline Grau 0 & ausência de contração não visível a olho nu, nem com luz rasante; \\
\hline Grau 1 & pequena mobilidade da pele \\
\hline Grau 2 & $\begin{array}{l}\text { a pele move-se mais, no qual se percebe levemente rugas, mas o } \\
\text { músculo entra em fadiga após algumas repetições }\end{array}$ \\
\hline Grau 3 & $\begin{array}{l}\text { a pele move-se mais claramente, o número de rugas aumenta bem } \\
\text { como sua profundidade. Após algumas repetições do movimento, } \\
\text { com alteração diferença de sincronia entre o lado saudável e o lado }\end{array}$ \\
\hline Grau 4 & $\begin{array}{l}\text { o movimento é efetuado de maneira ampla, simétrica e sincrônica } \\
\text { em relação ao lado saudável }\end{array}$ \\
\hline
\end{tabular}

Cada músculo foi avaliado individualmente através da solicitação da avaliadora por meio de cinco contrações e graduados em seguida. O músculo alvo ou grupo muscular e o comando para dado aos participantes estão descritos abaixo no quadro 3. 
Quadro 3. Músculo ou grupo muscular e o comando dado pela avaliadora

\begin{tabular}{|l|l|}
\hline \multicolumn{1}{|c|}{ Músculo ou grupo muscular } & \multicolumn{1}{c|}{ Comando } \\
\hline Músculo occipitofrontal & "Cara de assustado" \\
\hline Músculo corrugador do supercílio & "Cara de bravo" \\
\hline $\begin{array}{l}\text { Músculos transverso do nariz e piramidal do } \\
\text { nariz }\end{array}$ & "Cara de cheiro ruim" \\
\hline Músculo mirtiforme & "Raspar o bigode" \\
\hline Músculo orbicular do olho - porção palpebral & "Fechar os olhos suavemente" \\
\hline Músculo orbicular do olho - porção orbitária & "Fechar os olhos com força" \\
\hline $\begin{array}{l}\text { Músculos levantador do lábio superior, } \\
\text { zigomático maior e zigomático menor }\end{array}$ & "Sorriso aberto" \\
\hline Músculo risório & "Sorriso fechado" \\
\hline Músculo bucinador & "Comprimir a bochecha" \\
\hline Músculo abaixador do lábio inferior & "Fio dental na arcada inferior" \\
\hline Músculo mentoniano & "Empurrar o queixo para cima" \\
\hline $\begin{array}{l}\text { Músculos platisma e abaixador do ângulo da } \\
\text { boca }\end{array}$ & "Comissura labial para fora e \\
\hline Músculo orbicular dos lábios
\end{tabular}

A fim de se obter dados numéricos de comparação, ao final da avaliação, somou-se o grau atribuído (de 0 a 4 ) de cada comando solicitado, que resultou em um escore total que representa o desempenho geral dos músculos da mímica facial. Assim, o escore 52 (maior valor) indicou a melhor condição muscular da face e escore zero (menor valor), a pior condição.

\subsubsection{Análise Tridimensional Optoeletrônica do Movimento Facial}

Registro dos movimentos da expressão facial 
Os movimentos da mímica facial foram registrados pelo sistema de análise optoeletrônica tridimensional do movimento (BTS SMART System, Garbagnate, Milão, Itália). Esse sistema utiliza oito câmeras de alta resolução temporal, que são compostas por sensores no espectro de luz infravermelha (IR). No entorno dessas câmeras há LEDs (light emitting diode) que emitem luz IR, que possibilitam a captura do reflexo dessa luz proveniente de marcadores reflexivos posicionados na face do voluntário. Os marcadores utilizados neste trabalho possuíam diâmetro de 3,5 mm e peso desprezível. As coordenadas $\mathrm{X}, \mathrm{Y}$ e $Z$ de cada marcador utilizado foram registradas a cada 2 milissegundos (500 $\mathrm{Hz}$ de amostragem), com resolução espacial inferior a $0.5 \mathrm{~mm}$.

O indivíduo foi posicionado em frente ao conjunto de câmeras, sentado em cadeira de altura ajustável. O sistema não é invasivo e permite que o voluntário se movimente de forma confortável. Três câmeras de vídeo simples adicionais são utilizadas para controle do exame e futuro auxílio na análise dos dados. (Figura 4).

Figura 4. Voluntário posicionado em frente às oito câmeras de vídeo

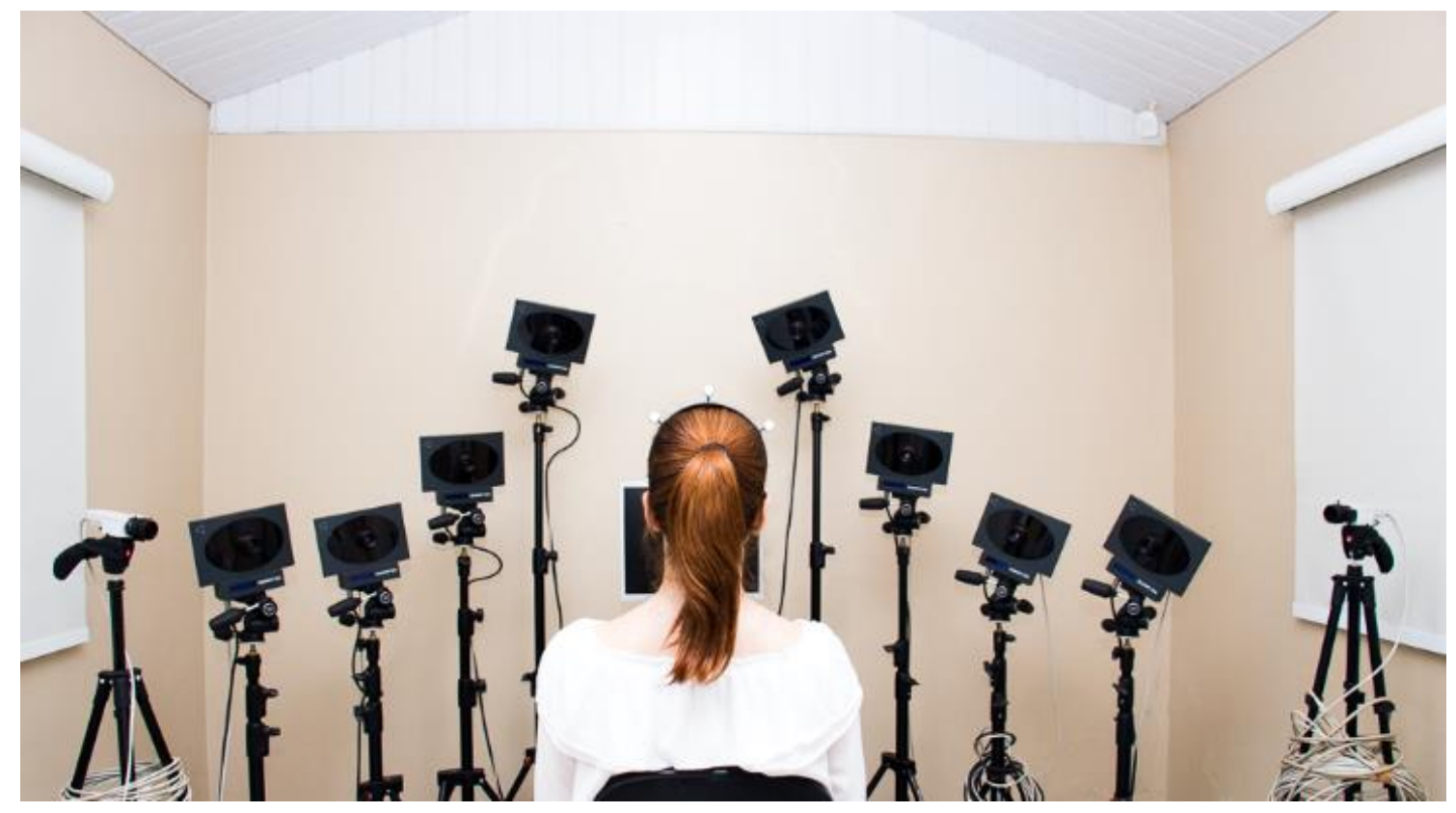

Os critérios para posicionamento dos marcadores foram estabelecidos seguindo a antropometria clássica (Farkas, 1994). Os pontos escolhidos estão descritos no quadro 4 e foram determinados com base em estudos anteriores 
(Sforza et al., 2010a; 2010b; 2012a; 2012b; 2014). Além dos pontos antropométricos, marcadores adicionais foram utilizados para criação de um sistema de referência a fim de eliminar matematicamente possíveis movimentos da cabeça durante os movimentos faciais, além de ser usado para padronizar a posição da cabeça entre os sujeitos. Por segurança, foram utilizados dois conjuntos de marcadores para o sistema de referência: um conjunto principal (frontoparietal direito, frontoparietal esquerdo e vértice, presos em uma tiara) e um conjunto alternativo (frontotemporal direito, frontotemporal esquerdo, glabela, tragus direito e tragus esquerdo) (Figura 5).

Quadro 4. Descrição dos pontos antropométricos de tecido mole facial utilizados segundo Farkas (1994) e algumas adaptações

\begin{tabular}{|c|c|}
\hline Ponto de referência & Descrição da localização do ponto \\
\hline Vértice (V) & $\begin{array}{c}\text { Ponto mais alto localizado na cabeça } \\
\text { quando a cabeça está orientada no plano de } \\
\text { Frankfurt. }\end{array}$ \\
\hline Frontoparietal direito (Fpd) & $\begin{array}{l}\text { Ponto localizado lateralmente } \\
\text { correspondente à região mediana dos ossos } \\
\text { frontal e temporal do lado direito. }\end{array}$ \\
\hline Frontoparietal esquerdo (Fpe) & $\begin{array}{l}\text { Ponto localizado lateralmente } \\
\text { correspondente à região mediana dos ossos } \\
\text { frontal e temporal do lado esquerdo. }\end{array}$ \\
\hline Superciliar direito (Scid) & $\begin{array}{l}\text { Ponto mais alto no limite superior da } \\
\text { sobrancelha direita. }\end{array}$ \\
\hline Superciliar esquerdo (Scie) & $\begin{array}{c}\text { Ponto mais alto no limite superior da } \\
\text { sobrancelha esquerda. }\end{array}$ \\
\hline Frontotemporal direito (Ftd) & $\begin{array}{l}\text { Ponto localizado lateralmente na testa na } \\
\text { região correspondente ao final da } \\
\text { sobrancelha do lado direito. }\end{array}$ \\
\hline Frontotemporal esquerdo (Fte) & $\begin{array}{l}\text { Ponto localizado lateralmente na testa na } \\
\text { região correspondente ao final da }\end{array}$ \\
\hline
\end{tabular}




\begin{tabular}{|c|c|}
\hline & sobrancelha do lado esquerdo. \\
\hline Glabela (G) & $\begin{array}{l}\text { Ponto mais proeminente da linha média } \\
\text { entre as sobrancelhas. }\end{array}$ \\
\hline Tragus direito $(\mathrm{Td})$ & $\begin{array}{l}\text { Ponto localizado no encaixe da margem } \\
\text { superior do tragus do lado direito. }\end{array}$ \\
\hline Tragus esquerdo (Te) & $\begin{array}{l}\text { Ponto localizado no encaixe da margem } \\
\text { superior do tragus do lado esquerdo. }\end{array}$ \\
\hline Sulco nasogeniano direito (Ngd) & $\begin{array}{l}\text { Ponto mediano localizado entre os pontos } \\
\text { da comissura labial e a curvatura alar do } \\
\text { lado direito. }\end{array}$ \\
\hline $\begin{array}{l}\text { Sulco nasogeniano esquerdo } \\
\qquad(\mathrm{Nge})\end{array}$ & $\begin{array}{l}\text { Ponto mediano localizado entre os pontos } \\
\text { da comissura labial e a curvatura alar do } \\
\text { lado esquerdo. }\end{array}$ \\
\hline Filtro da crista direito (Cphd) & $\begin{array}{l}\text { Ponto localizado na margem elevada do } \\
\text { filtro do lado direito. }\end{array}$ \\
\hline Filtro da crista esquerdo (Cphe) & $\begin{array}{l}\text { Ponto localizado na margem elevada do } \\
\text { filtro do lado esquerdo. }\end{array}$ \\
\hline Cheilion direito (Chd) & $\begin{array}{c}\text { Ponto localizado na comissura labial do lado } \\
\text { direito. }\end{array}$ \\
\hline Cheilion esquerdo (Che) & $\begin{array}{c}\text { Ponto localizado na comissura labial do lado } \\
\text { esquerdo. }\end{array}$ \\
\hline Lábio inferior direito (Lid) & $\begin{array}{l}\text { Ponto médio localizado abaixo da linha } \\
\text { vermelha do lado direito. }\end{array}$ \\
\hline Lábio inferior esquerdo (Lie) & $\begin{array}{c}\text { Ponto médio localizado abaixo da linha } \\
\text { vermelha do lado esquerdo. }\end{array}$ \\
\hline
\end{tabular}


Figura 5. Pontos antropométricos de tecido mole facial utilizados, segundo Farkas (1994) e adaptações

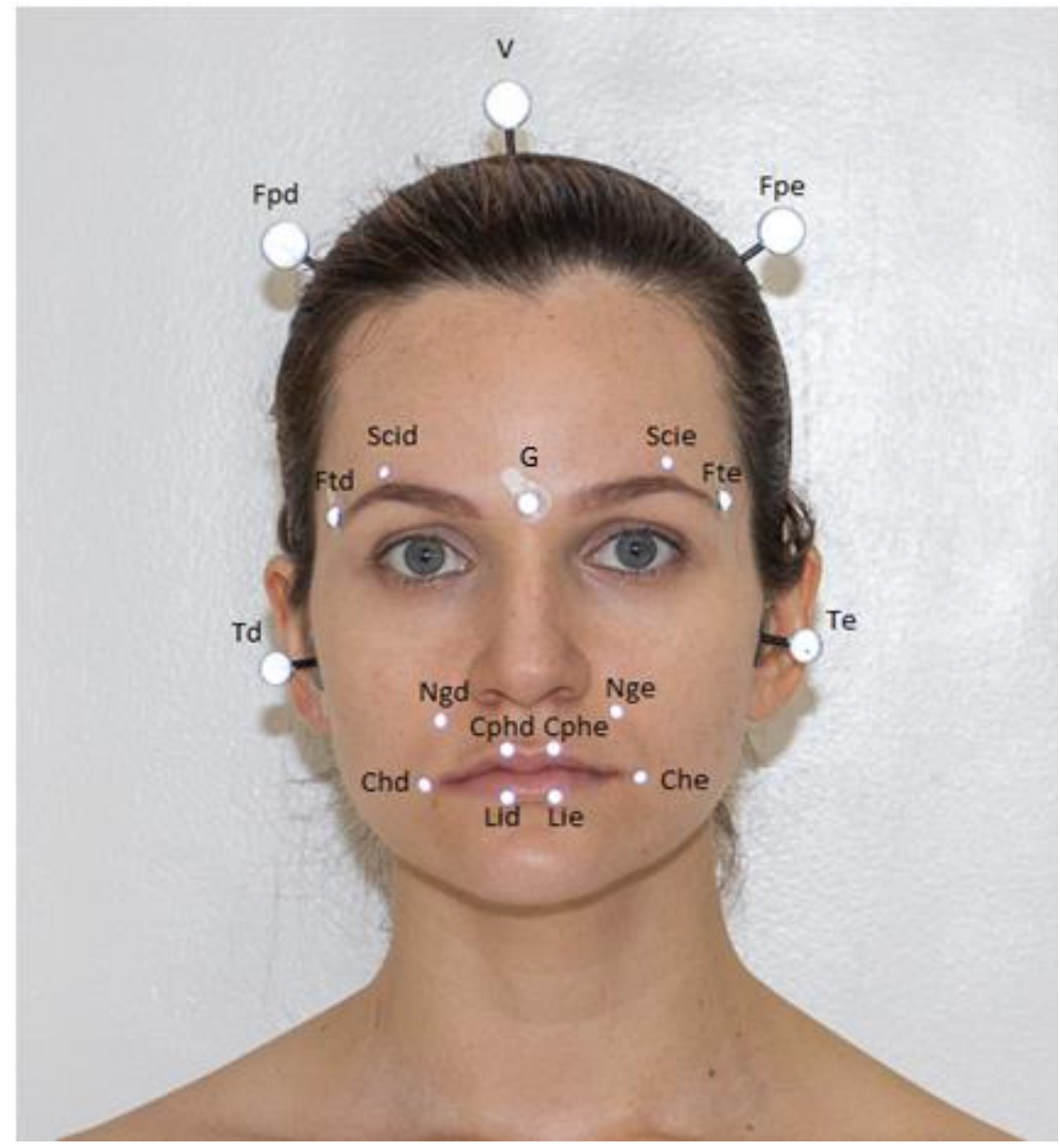

Movimentos faciais registrados

Cada prova foi explicada e demonstrada para os sujeitos, bem como solicitado que realizasse o movimento antes do início do exame. Ao total, seis provas foram realizadas a partir do repouso até a realização do movimento máximo e em seguida retornando a posição de repouso, segundo estudos realizados previamente (Sforza et al., 2010, 2012a, 2012b, 2014; Lee et al., 2015): 
- Movimento de elevar a testa (Surpresa - SP);

- Movimento de franzir a testa (Raiva - RV);

- Movimento de odor desagradável (Cheiro ruim - CR);

- Movimento de sorriso com os lábios abertos (Sorriso aberto - SA);

- Movimento de sorriso com os lábios fechados (Sorriso fechado - SF);

- Movimento de protrusão labial (Protrusão - PT).

Para cada participante, cinco repetições de cada expressão foram gravadas sem modificações das posições dos marcadores. O tempo médio para finalização do exame foi de 20 minutos.

\section{Análise dos movimentos faciais}

A análise dos dados da cinemática foi elaborada com base em estudos prévios (Sforza et al., 2010, 2012a, 2012b, 2014). Em nosso estudo a análise foi dividida em duas etapas. Na primeira, os registros passaram por um processamento de sinais para eliminação de possíveis ruídos (filtro Butterworth passa-baixo com frequência de corte de $8 \mathrm{~Hz}$ ) e seleção, pelo examinador, dos momentos de início e fim de cada prova realizada. Neste intervalo de tempo selecionado foi calculada a amplitude máxima do movimento de cada ponto em três eixos (X: látero-lateral; Y: ântero-posterior; Z: crânio-caudal). Todos os procedimentos foram realizados por meio de protocolos desenvolvidos no Software Analyzer (BTS SMART System, Garbagnate, Milão, Itália).

$\mathrm{Na}$ segunda etapa foram selecionados os pontos e eixos mais importantes relacionados a cada prova. Na figura 6 encontram-se os movimentos de mímica facial, bem como os eixos utilizados para cada prova. No quadro 5 são demonstrados os pontos utilizados em cada prova de mímica e o eixo analisado para cada uma delas. 
Figura 6. Repouso, movimentos de mímica e as coordenadas correspondentes. A. Repouso; B. Cara de surpresa; C. Cara de raiva; D. Cara de cheiro ruim; E. Sorriso aberto; F. Sorriso fechado; G. Protrusão labial
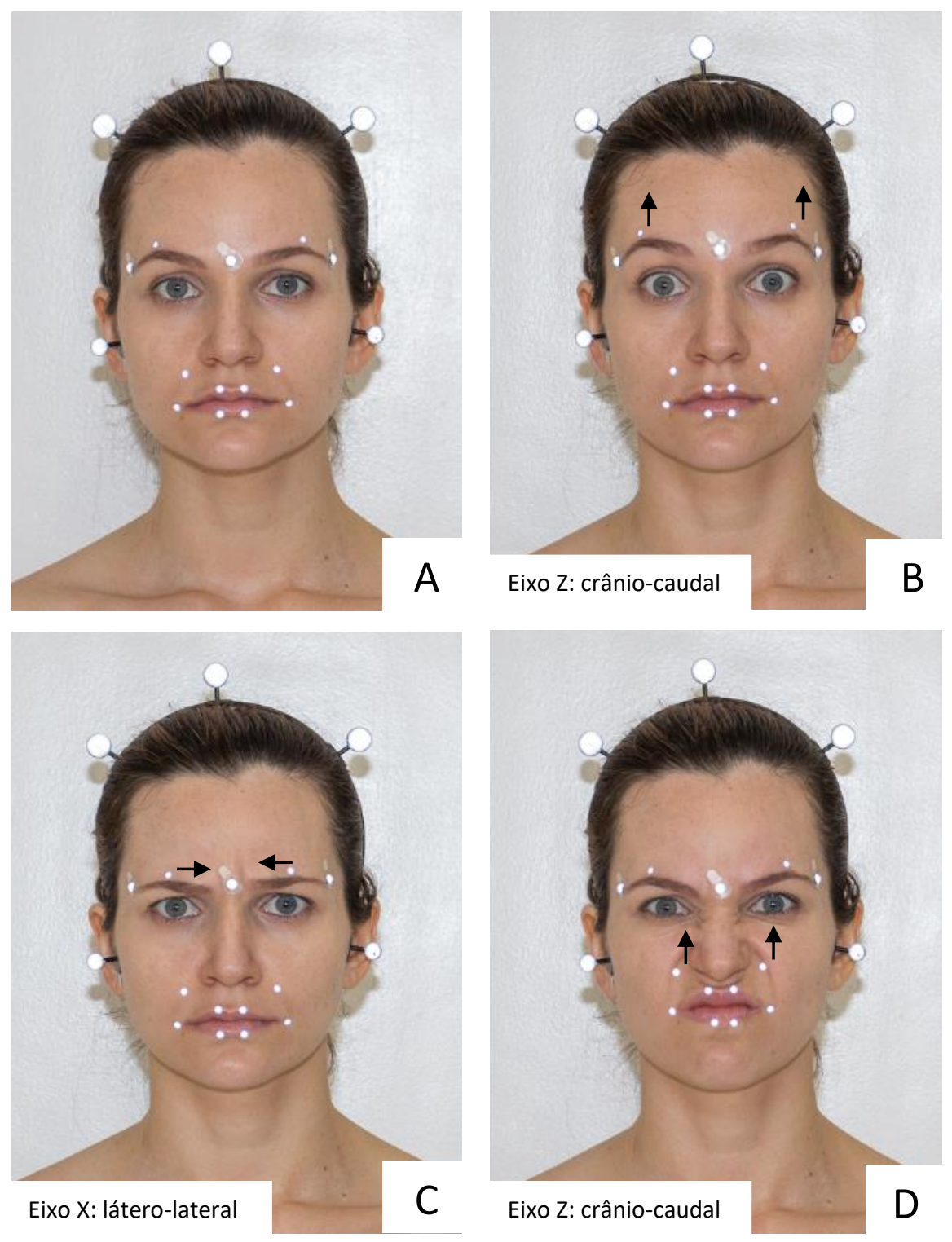

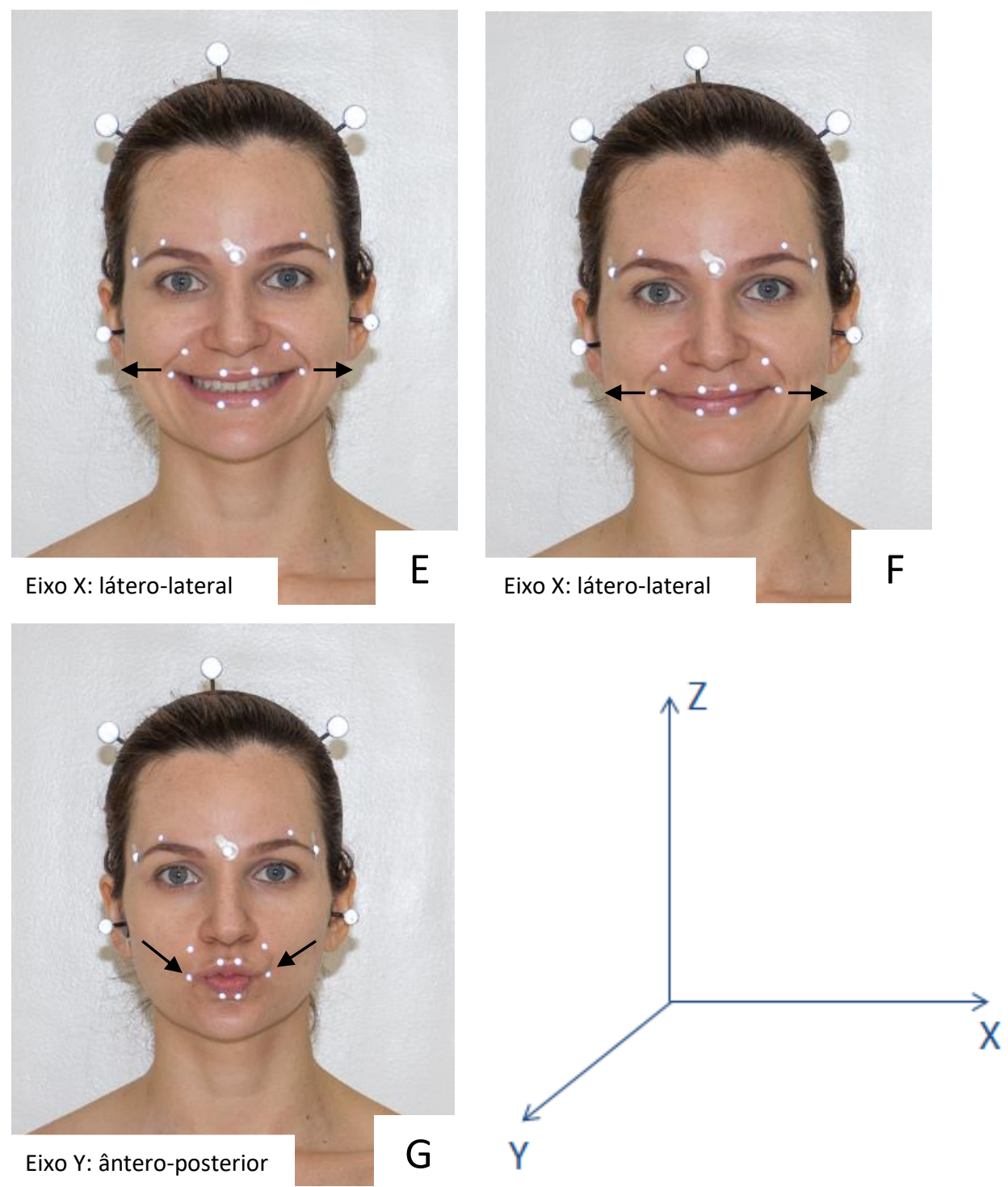

Quadro 5. Pontos antropométricos, prova de mímica e seu eixo correspondente.

\begin{tabular}{|c|c|c|}
\hline Ponto de referência & Prova de mímica & Eixo \\
\hline Scid e Scie & Surpresa & $\mathrm{Z}$ \\
\hline Scid e Scie & Raiva & $\mathrm{X}$ \\
\hline Ngd e Nge & Cheiro ruim & $\mathrm{Z}$ \\
\hline Chd e Che & Sorriso aberto & $\mathrm{X}$ \\
\hline Chd e Che & Sorriso fechado & $\mathrm{X}$ \\
\hline Lid e Lie & Protrusão labial & $\mathrm{Y}$ \\
\hline Cphd e Cphe & Protrusão labial & $\mathrm{Y}$ \\
\hline
\end{tabular}


Os valores de amplitude apresentados em milímetros $(\mathrm{mm})$ representam o deslocamento no eixo principal e no espaço 3D para o lado menor deslocamento ( $L$ menor) e lado de maior deslocamento ( $L$ maior) referente ao $G C$ e lados não paralisado (LN) e lado paralisado (LNP) para o GPFP. A variável simetria (S (\%)) foi calculada com o intuito de representar a simetria de amplitude entre os lados durante as provas de mímica facial (100\% simetria perfeita), segundo as equações abaixo, respectivamente para GC e GPFP:

$$
\begin{aligned}
& S(\%)=100 *\left(\frac{\text { Amplitude }(\mathrm{mm}) L_{\text {menor }}}{\text { Amplitude }(\mathrm{mm}) L_{\text {maior }}}\right) \\
& S(\%)=100 *\left(\frac{\text { Amplitude }(\mathrm{mm}) \mathrm{LP}}{\text { Amplitude }(\mathrm{mm}) \mathrm{LNP}}\right)
\end{aligned}
$$

As comparações entre grupos em cada prova foram efetuadas a partir da variável simetria $(\mathrm{S}(\%))$.

\subsection{Análise Estatística}

A análise estatística foi realizada e os resultados obtidos foram apresentados por mediana, média e desvio padrão na comparação entre os GC e GPFP, e para isso, o teste não paramétrico de Mann-Whitney foi utilizado. Comparou-se a QV entre os grupos, bem como entre os sexos; a mobilidade da mímica facial e a análise 3D do movimento facial para as seis provas.

O teste de correlação de Spearman foi utilizado para analisar as relações entre a QV e o desempenho da mímica e o grau da PFP segundo a escala de House e Brackmann (1985). O coeficiente de correlação avaliou os índices de incapacidade facial (físico e social) referentes à QV; a mobilidade da mímica facial geral e análise 3D para cada movimento avaliado. Além de correlacionar os índices de incapacidade facial com a mobilidade da mímica facial e com a análise 3D do movimento facial. 
Todas as análises foram realizadas por meio do Software JMP (SAS Institute Inc., Cary, NC, U.S.A.). Foi considerado nível de significância de 5\% $(P<0,05)$. 


\section{RESULTADOS}

\section{1. Índice de Incapacidade Facial (IIF)}

Diferenças significantes foram observadas, entre o GC e o GPFP, em relação aos índices de função física e de bem-estar social, com menores escores para o GPFP (Tabela 3).

Tabela 3. Mediana, média e desvio padrão do Índice de Incapacidade Facial referente à QV e diferença entre o grupo controle (GC) e paralisia facial periférica (GPFP)

\begin{tabular}{ccccc}
\hline $\begin{array}{c}\text { Índice de Incapacidade Facial } \\
\text { IIF-QV }\end{array}$ & & $\begin{array}{c}\text { GC } \\
(\mathbf{n}=\mathbf{2 8})\end{array}$ & $\begin{array}{c}\text { GPFP } \\
(\mathbf{n}=\mathbf{3 5})\end{array}$ & $\mathbf{P}$ \\
\hline \multirow{2}{*}{ Função Física } & Mediana & 100 & 55 & \\
& Média & 98,8 & 55,6 & $<0,0001^{*}$ \\
& DP & 2,6 & 19,5 & \\
Bem Estar Social & Mediana & 80 & 64 & \\
& Média & 77,9 & 63,8 & $0,0141^{*}$ \\
& DP & 14,5 & 23,6 &
\end{tabular}

P: probabilidade no teste de Mann Whitney para amostras não pareadas; $P<0,05^{\star}$ diferença estatisticamente significante. DP: desvio padrão. n: número de participantes.

Quando se investigou se o sexo interfere na $Q V$, verificamos que este tem influência apenas para o GPFP, no qual as mulheres apresentaram escores menores, indicando um prejuízo na QV no subíndice social, como apresentado na tabela 4. 
Tabela 4. Diferença entre os sexos pelo Índice de Incapacidade Facial (IIF) referente à qualidade de vida $(\mathrm{QV})$ dos grupos controle $(\mathrm{GC})$ e paralisia facial periférica (GPFP)

\begin{tabular}{ccccc}
\hline & & \multicolumn{2}{c}{ Sexo } \\
\cline { 3 - 5 } & & F & M & P \\
\hline Grupo & IIF-QV & Média (DP) & Média (DP) & \\
\hline GC & Função Física & $97,91( \pm 3,34)$ & $99,37( \pm 1,7)$ & 0,18 \\
& Bem Estar Social & $73,33( \pm 16,91)$ & $81,25( \pm 11,84)$ & 0,16 \\
\multirow{2}{*}{ GPFP } & Função Física & $56( \pm 18,24)$ & $55,25( \pm 20,80)$ & 0,60 \\
& Bem Estar Social & $54,66( \pm 24,12)$ & $70,6( \pm 21,29)$ & $0,046^{\star}$
\end{tabular}

$\mathrm{P}$ : probabilidade no teste de Mann Whitney para amostras não pareadas; $\mathrm{P}<0,05^{*}$ diferença estatisticamente significante. DP: desvio padrão; F: feminino; M: masculino.

\subsection{Avaliação da Mobilidade da Mímica Facial (AMMF)}

Em relação à mímica facial, menores escores foram observados no GPFP, comparados ao GC, com diferenças significativas, quando se comparou isoladamente cada contração muscular após os comandos avaliados e para o escore total, como verificado na tabela 5 . 
Tabela 5. Mediana, média e desvio padrão na Avaliação da Mobilidade da Mímica Facial (AMMF) e diferença entre os grupos controle (GC) e paralisia facial periférica (GPFP) para cada grupo muscular avaliado e escore total

\begin{tabular}{|c|c|c|c|c|c|c|c|}
\hline \multirow[b]{3}{*}{ AMMF } & \multicolumn{6}{|c|}{ GRUPO } & \multirow[b]{3}{*}{$\mathbf{P}$} \\
\hline & \multicolumn{3}{|c|}{$\begin{array}{c}\text { GC } \\
\text { Escore }\end{array}$} & \multicolumn{3}{|c|}{$\begin{array}{l}\text { GPFP } \\
\text { Escore }\end{array}$} & \\
\hline & Mediana & Média & DP & Mediana & Média & DP & \\
\hline Assustado & 4 & 3.9 & 0.6 & 1 & 1.6 & 1.2 & $<, 0001^{*}$ \\
\hline Bravo & 4 & 4 & 0.2 & 1 & 1.3 & 1.2 & $<, 0001^{*}$ \\
\hline Cheiro Ruim & 4 & 3.9 & 0.4 & 1 & 1.1 & 1.2 & $<, 0001^{*}$ \\
\hline Raspar bigode & 4 & 4 & 0 & 1 & 1.1 & 1.1 & $<, 0001^{*}$ \\
\hline $\begin{array}{l}\text { Fechar olhos } \\
\text { suave }\end{array}$ & 4 & 4 & 0 & 2 & 2.1 & 1 & $<, 0001^{*}$ \\
\hline $\begin{array}{l}\text { Fechar olhos } \\
\text { força }\end{array}$ & 4 & 4 & 0 & 3 & 2.5 & 1 & $<, 0001^{*}$ \\
\hline Sorriso aberto & 4 & 4 & 0.2 & 0 & 0.9 & 1.2 & $<, 0001^{*}$ \\
\hline Sorriso fechado & 4 & 4 & 0 & 1 & 0.9 & 1.1 & $<, 0001^{*}$ \\
\hline Bochechas & 4 & 3.9 & 0.3 & 0 & 0.6 & 1 & $<, 0001^{*}$ \\
\hline Dentes inferiores & 4 & 3.9 & 0.3 & 0 & 0.8 & 1.1 & $<, 0001^{*}$ \\
\hline $\begin{array}{l}\text { Queixo para } \\
\text { cima }\end{array}$ & 4 & 3.7 & 0.9 & 2 & 1.6 & 0.9 & $<, 0001^{*}$ \\
\hline $\begin{array}{c}\text { Comissura para } \\
\text { fora e para baixo }\end{array}$ & 4 & 3.9 & 0.3 & 1 & 1.1 & 1 & $<, 0001^{*}$ \\
\hline Fazer Bico & 4 & 4 & 0 & 1 & 1.5 & 0.9 & $<, 0001^{*}$ \\
\hline Escore total & 52 & 51,2 & 2 & 13 & 17,1 & 12 & $<, 0001^{*}$ \\
\hline
\end{tabular}

\subsection{Análise tridimensional do movimento facial}

A análise tridimensional dos movimentos de mímica facial mostrou diferença significante entre os grupos para os seis movimentos propostos neste estudo, na relação dos pontos específicos, tanto para seu eixo unidimensional, como na análise 3D. A tabela 6 expõe os valores obtidos, em que a simetria 
destes números (\%) quanto mais próxima ao valor de 100, maior a simetria entre os lados da face.

Tabela 6. Valores entre os lados da face e sua razão, na comparação entre os grupos controle (GC) e paralisia facial periférica (GPFP) para as seis provas de mímica facial

GC

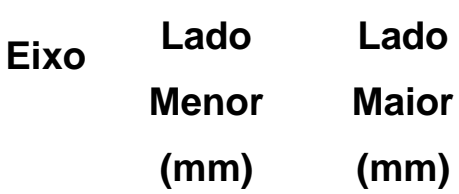

GPFP

\section{Simetria}

(\%)
LNP Simetria

$(\mathrm{mm})$
(\%)

\begin{tabular}{ccccccccc}
\hline SP & Z & $13,6 \pm 4,1$ & $14,1 \pm 3,7$ & $89,6 \pm 13,6$ & $4,6 \pm 3,0$ & $11,4 \pm 2,9$ & $40,1 \pm 25,7$ & $<.0001$ \\
(sci) & 3D & $14,2 \pm 4,1$ & $14,6 \pm 3,8$ & $90,0 \pm 9,8$ & $5,1 \pm 2,9$ & $12,1 \pm 3,2$ & $42,2 \pm 23,8$ & $<.0001$ \\
RV & X & $6,8 \pm 1,8$ & $7,0 \pm 1,4$ & $87,8 \pm 11,9$ & $0,7 \pm 2,0$ & $1,5 \pm 6,7$ & $24,8 \pm 22,0$ & $<.0001$ \\
(sci) & 3D & $8,5 \pm 2,3$ & $8,9 \pm 1,4$ & $86,7 \pm 11,9$ & $2,2 \pm 1,6$ & $8,7 \pm 2,9$ & $25,7 \pm 18,2$ & $<.0001$ \\
CR & Z & $11,5 \pm 2,9$ & $12,0 \pm 2,5$ & $91,2 \pm 8,1$ & $3,1 \pm 2,0$ & $9,6 \pm 4,1$ & $36,8 \pm 30,4$ & $<.0001$ \\
(ng) & 3D & $12,0 \pm 2,5$ & $12,5 \pm 2,4$ & $91,9 \pm 8,1$ & $4,3 \pm 1,7$ & $10,0 \pm 4,0$ & $49,1 \pm 28,0$ & $<.0001$ \\
SA & X & $7,9 \pm 2,1$ & $8,4 \pm 1,6$ & $82,9 \pm 14,2$ & $0,1 \pm 2,7$ & $1,8 \pm 7,4$ & $8,2 \pm 43,6$ & $<.0001$ \\
(ch) & 3D & $16,8 \pm 2,9$ & $17,0 \pm 2,1$ & $92,2 \pm 7,1$ & $5,2 \pm 3,0$ & $15,4 \pm 3,8$ & $-36,4 \pm 25,0$ & $<.0001$ \\
SF & X & $6,4 \pm 2,4$ & $6,8 \pm 2,1$ & $80,5 \pm 15,8$ & $0,3 \pm 2,3$ & $1,7 \pm 5,9$ & $4,6 \pm 49,7$ & $<.0001$ \\
(ch) & 3D & $14,8 \pm 3,9$ & $15,2 \pm 3,6$ & $90,5 \pm 8,8$ & $4,9 \pm 3,4$ & $13,6 \pm 3,6$ & $37,2 \pm 25,9$ & $<.0001$ \\
PT & Y & $10,0 \pm 2,7$ & $10,2 \pm 2,6$ & $95,5 \pm 4,0$ & $6,7 \pm 2,2$ & $8,5 \pm 2,6$ & $78,8 \pm 14,8$ & $<.0001$ \\
(cph) & 3D & $11,3 \pm 2,8$ & $11,3 \pm 2,9$ & $86,8 \pm 22,5$ & $8,9 \pm 2,7$ & $10,6 \pm 3,3$ & $86,6 \pm 17,0$ & $<.0001$ \\
PT & Y & $7,9 \pm 2,9$ & $8,0 \pm 3,2$ & $88,1 \pm 12,4$ & $5,7 \pm 3,1$ & $7,8 \pm 3,1$ & $69,3 \pm 21,8$ & $<.0001$ \\
(li) & 3D & $10,6 \pm 2,8$ & $10,7 \pm 2,5$ & $91,8 \pm 5,5$ & $8,9 \pm 2,7$ & $10,6 \pm 3,3$ & $84,1 \pm 14,9$ & 0,0065
\end{tabular}

P: probabilidade no teste de Mann Whitney para amostras não pareadas; $\mathrm{P}<0,05^{\star}$ diferença estatisticamente significante. SP: surpresa; RV: raiva; CR: cheiro ruim; SA: sorriso aberto; SF: sorriso fechado; PT: protrusão labial; sci: superciliar; ng: nasogeniano; ch: comissura; cph: filtro da crista; li: lábio inferior. Eixo Z: craniocaudal; X: latero-lateral; Y: anterô-posterior; 3D: tridimensional; lado menor: menor deslocamento ao movimento; lado maior: maior deslocamento ao movimento direito; LP: lado paralisado; LNP: lado não paralisado; simetria (\%): simetria entre os lados das faces.

\subsection{Correlação entre as variáveis}


Foram encontradas correlações negativas entre o grau da PFP e as variáveis de QV para o índice de função física do questionário IIF-QV, sem correlação entre o índice de bem estar social (Tabela 7).

Tabela 7. Correlação entre o grau da paralisia facial segundo a escala de comprometimento motor de House-Brackmann (1985) e o Índice de Incapacidade Facial (IIF) referente à qualidade de vida (QV)

\begin{tabular}{ccc}
\hline & \multicolumn{2}{c}{ Grau de comprometimento motor } \\
\cline { 2 - 3 } & $\rho$ & $\mathrm{P}$ \\
\hline IIF - Função Física & $-0,40$ & $0,01^{*}$ \\
IIF - Bem Estar Social & $-0,07$ & 0,66
\end{tabular}

* diferença estatisticamente significante. $\rho$ : coeficiente de correlação de Spearman; $\mathrm{P}<0,05^{*}$ diferença estatisticamente significante.

Encontrou-se correlação negativa entre idade e QV para o GPFP no subíndice de função física, como se observa na tabela 8.

Tabela 8. Correlação entre idade e o Índice de Incapacidade Facial (IIF) referente à qualidade de vida $(\mathrm{QV})$ para os grupos controle $(\mathrm{GC})$ e paralisia facial periférica (GPFP)

\begin{tabular}{cccc}
\hline Grupo & IIF-QV & \multicolumn{2}{c}{ Idade } \\
& & $\rho$ & $P$ \\
\hline \multirow{2}{*}{ GC } & Função Física & $-0,05$ & 0,79 \\
& Bem Estar Social & 0,24 & 0,20 \\
\multirow{2}{*}{ GPFP } & Função Física & $-0,45$ & $0,005^{\star}$ \\
& Bem Estar Social & $-0,23$ & 0,16
\end{tabular}

*diferença estatisticamente significante. $\rho$ : coeficiente de correlação de Spearman; $\mathrm{P}<0,05^{*}$ diferença estatisticamente significante.

Houve correlação entre a AMMF e a IIF-QV no índice de função física e correlação entre a AMMF e o grau de comprometimento motor (Tabela 9) 
Tabela 9. Correlação entre a Avaliação da Mobilidade da Mímica Facial (AMMF) com o Índice de Incapacidade Facial (IIF) referente à qualidade de vida (QV) e o grau da paralisia facial segundo a escala de comprometimento motor de HouseBrackmann (1985)

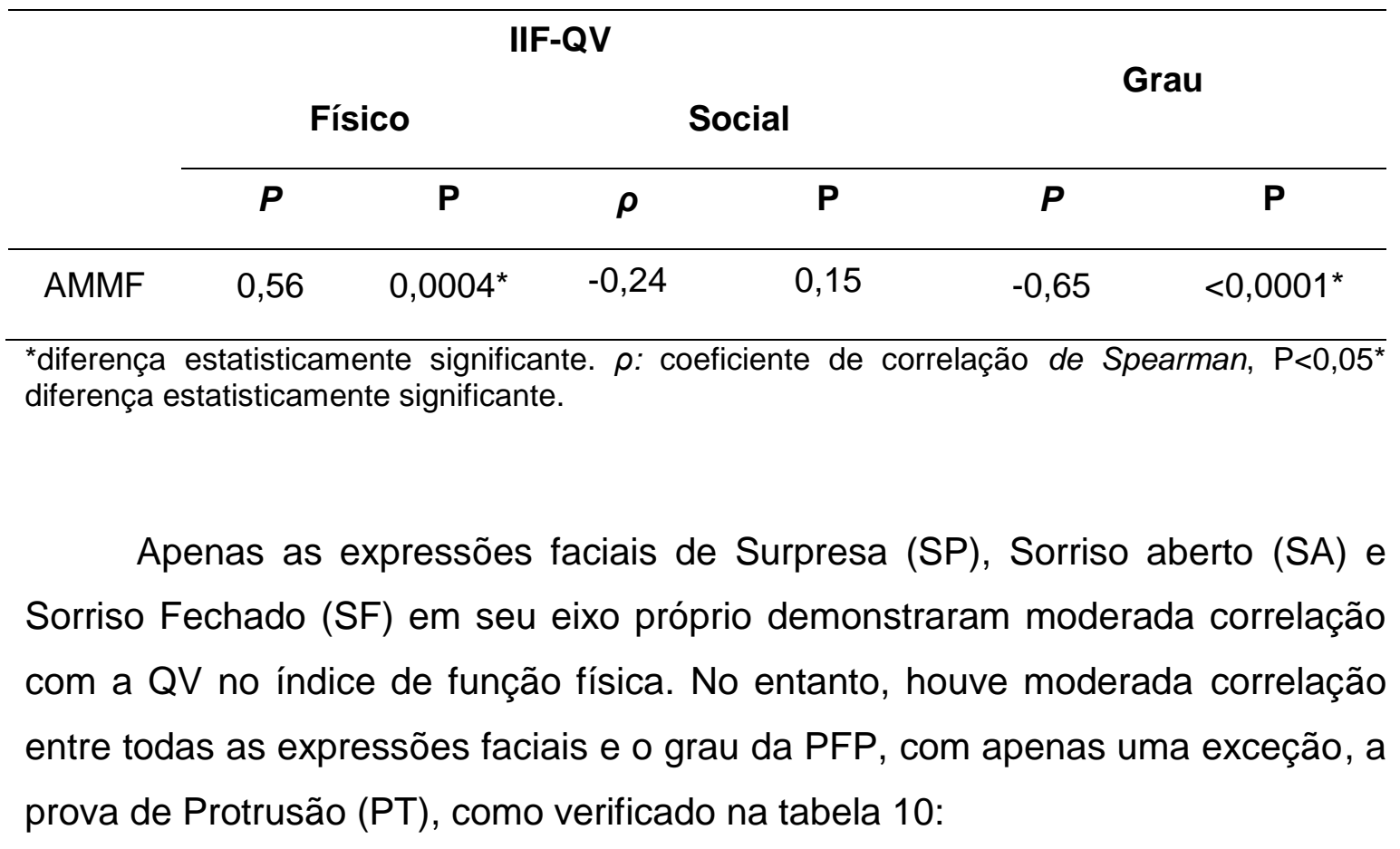


Tabela 10. Correlação entre o Índice de Incapacidade Facial (IIF) referente à qualidade de vida $(\mathrm{QV})$, grau de comprometimento motor e as expressões faciais em seus eixos e relação tridimensional (3D)

\section{IIF-QV}

Grau

Físico

Social

\begin{tabular}{|c|c|c|c|c|c|c|c|}
\hline & Eixo & $\rho$ & $\mathbf{P}$ & $\rho$ & $\mathbf{P}$ & $P$ & $\mathbf{P}$ \\
\hline SP & Z & 0,44 & $0,006^{*}$ & $-0,16$ & 0,34 & $-0,52$ & $0,001^{*}$ \\
\hline (sci) & $3 D$ & 0,43 & $0,008^{*}$ & $-0,11$ & 0,49 & $-0,50$ & $0,002^{*}$ \\
\hline $\mathrm{RV}$ & $x$ & $-0,28$ & 0,11 & 0,08 & 0,64 & 0,70 & $0,0001^{*}$ \\
\hline (sci) & $3 D$ & 0,24 & 0,16 & $-0,03$ & 0,82 & $-0,65$ & $<, 0001^{*}$ \\
\hline $\mathrm{CR}$ & Z & 0,32 & 0,06 & 0,07 & 0,68 & $-0,52$ & $0,001^{*}$ \\
\hline (ng) & $3 D$ & 0,11 & 0,49 & 0,04 & 0,81 & $-0,26$ & 0,11 \\
\hline SA & $x$ & $-0,36$ & $0,03^{*}$ & 0,17 & 0,32 & 0,48 & $0,002^{*}$ \\
\hline (ch) & $3 D$ & 0,37 & $0,02^{*}$ & $-0,005$ & 0,97 & $-0,52$ & $0,001^{*}$ \\
\hline SF & $X$ & $-0,46$ & $0,005^{\star}$ & 0,23 & 0,17 & 0,37 & $0,03^{*}$ \\
\hline (ch) & $3 D$ & 0,22 & 0,20 & $-0,0006$ & 0,99 & $-0,42$ & $0,01^{*}$ \\
\hline PT & $Y$ & 0,04 & 0,80 & 0,07 & 0,68 & $-0,05$ & 0,75 \\
\hline (cph) & $3 D$ & 0,03 & 0,86 & $-0,05$ & 0,76 & 0,10 & 0,53 \\
\hline $\mathrm{PT}$ & $Y$ & $-0,01$ & 0,93 & $-0,14$ & 0,39 & $-0,18$ & 0,29 \\
\hline (li) & $3 D$ & $-0,003$ & 0,98 & $-0,21$ & 0,20 & $-0,10$ & 0,56 \\
\hline
\end{tabular}

$\rho$ : coeficiente de correlação de Spearman; P: probabilidade no teste de Mann Whitney para amostras não pareadas; $\mathrm{P}<0,05^{*}$ diferença estatisticamente significante. SP: surpresa; $\mathrm{RV}$ : raiva; CR: cheiro ruim; SA: sorriso aberto; SF: sorriso fechado; PT: protrusão; sci: superciliar; ng: nasogeniano; ch: comissura; cph: filtro da crista; li: lábio inferior. Eixo Z: crânio-caudal; X: laterolateral; Y: anterô-posterior; 3D: tridimensional. 


\section{DISCUSSÃO}

Os achados deste estudo demonstraram diferença na QV entre os GC e GPFP avaliados pelo questionário específico IIF em disfunção do NF nos subíndices função física e bem estar social. Desta forma, nossa hipótese pôde ser confirmada. Na prática clínica, os sujeitos portadores de PFP, em sua grande maioria, apresentam queixas relacionadas à aparência física, em maior ou menor escala, o que os impede de praticar atividades de vida diária simples devido ao prejuízo quanto aos aspectos funcionais e à grande influência na autoestima e nas questões emocionais, o que acarreta um afastamento deste indivíduo da sociedade.

Bem como em nosso estudo, Nellis et al. (2016) encontraram resultados semelhantes, ainda que englobasse diversas etiologias e que não utilizasse uma escala própria para averiguação da QV em PFP, e sim uma escala de classificação analógica visual, não específica para a doença em questão.

Györi et al. (2018) ressaltaram a importância de se utilizar instrumentos específicos, validados para casos de paralisia facial, pois estes captam a perspectiva do paciente sobre os comprometimentos funcionais e sociais associados à doença que o aflige.

Com relação ao sexo e QV, em nosso estudo as mulheres portadoras de paralisia facial em fase aguda parecem se abalar mais no âmbito social, o que poderia ser justificado pela vaidade feminina. Nos achados de Volk et al. (2016), o sexo feminino também demonstrou menor QV pelo questionário IIF, no entanto estes casos encontravam-se em fase crônica. Outros estudos corroboram os nossos resultados com relação à menor QV entre as mulheres, bem como uma associação da paralisia facial ao aumento da depressão (Kleiss et al., 2015; Nellis et al., 2016). No entanto, estes diferem quanto à metodologia, pois aplicam outros questionários para tal investigação, além de inserirem diversas etiologias de PFP e durante a fase crônica da doença.

No que se refere à idade, nossos achados identificaram a correlação negativa entre idade e QV, para a função física, dos portadores de paralisia facial, o que poderia ser justificado pela maior dificuldade no controle motor das funções orais. A literatura concorda com esses resultados ainda que diferem 
quanto a fase da PFP, suas etiologias e a faixa etária média por eles estudada (Kleiss et al., 2015; Volk et al., 2016). Em contrapartida, Leong e Lesser (2015) não encontraram correlação entre a idade e a QV destes pacientes, porém, os casos envolvidos se referiam a paralisia facial em casos pós-cirurgicos de schwannoma vestibular em fase crônica.

Apesar das diferenças existentes entre a QV e o sexo e suas correlações com a idade, a gravidade da paralisia facial e os índices de QV foi o fator de nosso maior interesse.

Nossos achados mostram uma correlação inversamente significante entre a QV e a gravidade da doença, que se deve ao fato de que quanto maior o escore do questionário, melhor a QV, e quanto maior o grau atribuído ao paciente, maior a disfunção facial que este enfrenta, principalmente no aspecto físico, que resulta na inabilidade no controle motor oral.

Assim como em nosso estudo, a correlação mais significante de grau e QV na PFP foi encontrada na fase inicial da doença (Prats-Golczer et al., 2017), ainda que diferissem quanto à sua etiologia. Díaz-Aristizabal et al. (2017) em seu experimento utilizaram uma escala de classificação de gravidade da doença diferente da nossa, no entanto correlacionaram igualmente a QV de ambos os subíndices do IIF com a gravidade da disfunção nervosa. Outros estudos que avaliaram o grau de comprometimento motor pela escala de House-Brackmann, como nos propusemos, ainda que diferissem de nosso estudo com relação à etiologia da PFP e a fase da doença, verificaram a correlação negativa existente entre o questionário IIF e o grau do comprometimento motor (Volk et al., 2016).

Não houve correlação entre o grau da PFP e a QV para o aspecto de bem-estar social. Isso pode ser justificado pelo fato de que, apesar da função física interferir na QV, o âmbito social dependerá de como esses indíviduos interpretam, lidam e se incomodam com a doença, assim como pelas orientações que recebem sobre o percurso da doença, seu prognóstico e as formas de reabilitação. Cabe destacar que os participantes foram atendidos em um serviço multiprofissional especializado e foram orientados em relação a esses aspectos.

Além disso, nosso estudo se refere à pacientes com PFP em fase aguda, momento este em que as possíveis sequelas da doença ainda não estão 
estabelecidas e o seu prognóstico é mais favorável. Todavia, tais resultados se repetiram no estudo de Volk et al. (2016) no qual o âmbito social não foi afetado na fase crônica em casos de etiologias diversas, o que nos sugere que o bem estar social pode não ser prejudicado pela fase da doença.

A gravidade da disfunção do NF e a correlação com os índices de QV foram interesse de vários outros trabalhos contidos na literatura. No entanto, estes utilizaram uma ferramenta de avaliação da QV diferente da utilizada neste estudo. Apesar disso, todos estes vão de encontro com os nossos resultados, com evidências de correlação inversa entre estas duas variáveis ( $\mathrm{Ng}, \mathrm{Ngo}, 2013$; Kleiss et al., 2015).

Nellis et al. (2016) descobriram que pacientes com paralisia facial, particularmente aqueles com maior grau de disfunção facial, tiveram escores de depressão significativamente maiores, menor atratividade autorreferida, escores de humor e índices de QV mais baixos comparados aos sujeitos sem paralisia facial. Assim como Arslan et al. (2018) que além de depressão, encontraram sintomas de ansiedade e desesperança nesses pacientes, mas que estas podem ser superadas com a recuperação da doença.

Um estudo foi realizado para medir o impacto da expressão facial prejudicada no olhar do observador casual (Ishii, 2018), no qual uma face com paralisia facial pode ser classificada com efeito negativo, além de o grau da paralisia interferir nesse julgamento. Em casos mais graves, os indivíduos foram identificados por observadores leigos como menos felizes do que aqueles com gravidade menor (Ishii et al., 2011; Bogart, Tickle-Degnen, Ambady, 2014) Assim, um paciente tentando expressar uma emoção positiva pode, em vez disso, ser percebido negativamente na sociedade pelo observador (Ishii et al., 2018).

Ademais, a gravidade da paralisia facial foi um fator que ajudou pessoas leigas a identificarem mais facilmente a doença em questão, no qual a idade dificultou a detecção do lado acometido; a boca e o sorriso foram a área e a expressão facial, respectivamente, relatadas como menos naturais (Mun et al., 2015). 
A face paralisada é significantemente menos atraente do que uma face normal, e pode transmitir a impressão de angústia, desconfiança e menor inteligência às pessoas que a observam (Ishii et al., 2012; Li et al., 2016).

A literatura traz que a QV dos indivíduos portadores de PFP é pior, mas que independente do tratamento utilizado para a recuperação, os índices de QV melhoram significantemente (Luijmes et al., 2017).

Um estudo demonstrou que a fala e a participação comunicativa de pacientes com paralisia facial é prejudicada, com influências na QV. Com isso, os autores incentivam adicionar estas metas aos tratamentos e cuidados desses sujeitos (Kim et al., 2018). Outro aspecto significante e por vezes esquecido quando se fala em QV destes pacientes é o impacto psicossocial na vida dos familiares, conjugê e amigos destes que lidam com a doença em questão (Luijmes et al., 2018).

Além disso, para completar as equipes multidisciplinares que tratam pacientes com esta doença, deve fazer parte um psicólogo especializado nas consequências psicossociais da paralisia facial, como depressão, baixa autoestima e ansiedade. $\mathrm{O}$ acompanhamento psicológico para todos os pacientes e principalmente àqueles que sofrem com a paralisia facial de longa duração poderia melhorar a disfunção psicossocial (Kleiss et al., 2015).

Na prática clínica, a avaliação do grau da paralisia facial é realizada com escalas que graduam e descreverem a severidade da paralisia e são utilizadas para avaliar o desempenho muscular e acompanhar seu processo de recuperação. Fattah et al. (2015) revisaram os instrumentos para graduação do NF desenvolvidos a fim de documentar sua função, monitorar sua recuperação e facilitar a comunicação entre os profissionais. Apesar disso, há limitações quanto ao grau de subjetividade, confiabilidade e aplicabilidade. Ainda assim, tais escalas permanecem como sendo as mais utilizadas para a avaliação funcional facial. A escala proposta por House e Brackmann (1985) é classificada como escala bruta e avalia a função motora facial global.

Beurskens e Heymans (2006) utilizaram a classificação de gravidade de House e Brackmann e também a classificação de Sunnybrook para avaliar a simetria facial em casos de paralisia facial crônica. Por estas classificações, os 
autores puderam mensurar a diminuição do grau da paralisia facial e a recuperação da simetria pós-terapia de mímica facial mesmo em casos tardios.

Alguns estudos utilizaram escalas para avaliar o grau da paralisia facial e como parâmetro para identificar melhora no curso da doença (Zaki, et al., 2018; van Veen et al., 2018). Outros ainda utilizam para a avaliação de escores clínicos atribuídos à movimentos alvos (Salles, Todelo, Ferreira, 2009; Sassi et al., 2011; Wenceslau et al., 2016). No entanto, esses estudos não levam em consideração a individualidade de cada músculo, em como a reabilitação pode ser direcionada para determinada região facial ou função específica.

Por isso, nos propomos a utilizar a escala House e Brackmann apenas como escala de gravidade para a PFP. Para a avaliação da função muscular mais precisa, buscamos um método que individualizasse cada músculo ou grupo de músculos referentes às expressões faciais específicas, que pudessem nos orientar o quanto o músculo encontra-se ineficiente na sua função de mímica na expressividade e, consequentemente, relacionado à função e o quanto impacta a vida do sujeito com a doença.

A mobilidade da mímica facial (AMMF) proposta por Chevalier et al. (1987) e adaptada por Fouquet (2000) nos permitiu conhecer o comportamento muscular individualizado. Quando avaliamos os músculos e os agrupamos em um escore geral, encontramos diferenças significantes entre os GC e GPFP. O mesmo ocorreu quando se investigou cada músculo ou grupos musculares em diferentes provas de mímica facial. O grupo com PFP demonstrou valores significantemente menores que o GC mesmo se tratando de uma escala com escores mais baixos, com variação de 0 a 4.

Fonseca et al. (2015) utilizou as escalas de House e Brackmann e a avaliação de Chevalier et al. (1987) para avaliar a concordância inter e intra examinadores nos pacientes com comprometimento do NF. Ambas as escalas se mostraram boas em concordância e usuais por parte dos avaliadores com a facilidade e relevância de aplicabilidade.

Dessa forma, o processo terapêutico poderá ser melhor preconizado e direcionado para a região em déficit, uma vez que se conhece a capacidade individual de cada músculo. Estudos confirmaram a eficácia e os efeitos benéficos dos exercícios de mímica facial associados ou não a biofeedback com 
espelhos ou eletromiografia comparados aos grupos que não receberam intervenção (Ross et al., 1991; Segal et al., 1995; Nakamura et al., 2003).

Além disso, em nosso estudo encontramos correlação significante entre a mobilidade da musculatura facial e o grau da paralisia facial, e também correlação com o subíndice de função física do IIF. Isso nos demonstra que a gravidade da PFP interfere no desempenho da musculatura facial, além de acarretar dificuldades físicas, que refletem na QV desse indivíduo. Sassi et al. (2011) não encontraram correlação entre os subíndices da QV e a assimetria facial vistos por análise eletromiográfica em pacientes com paralisia facial há mais de dois anos. O tempo transcorrido pela doença poderia indicar que estes pacientes, acometidos há mais de dois anos, já teriam adaptado a musculatura facial a desempenhar suas funções orais da forma como pudessem, compensando possíveis dificuldades. No presente estudo, a maioria dos participantes (89\%) foi avaliada em menos de um mês de acometimento do NF, sem que houvesse ainda possíveis compensações musculares.

No entanto, é importante ressaltar que mesmo em casos de PFP de longa duração, os pacientes que receberam intervenção tardia de terapias combinadas para mímica e expressividade emocional, tiveram melhora nos aspectos de rigidez, mobilidade labial e melhora na QV verificada pelo IIF, em ambos os subíndices (Beurskens, Heymans, 2003).

A capacidade de limpeza do vestíbulo oral e a eficiência mastigatória encontraram-se diminuídas em portadores de PFP quando comparados aos controles, evidenciando prejuízo na alimentação e na higiene oral e até pode resultar em doenças bucais. No entanto, estas habilidades podem se recuperar principalmente com a resolução da paralisia facial (Kato et al., 2013). Conhecer como os músculos interferem em cada função de mímica facial auxiliará na identificação e compreensão das queixas, bem como nas dificuldades específicas de cada sujeito, o que trará maior embasamento para a reabilitação muscular.

Outras características que podem ser afetadas pela PFP são a comunicação e o controle salivar. No entanto, Moveraré et al. (2017) não encontraram correlações entre estas variáveis com a gravidade da doença. Mesmo assim, os autores sugerem que durante a prática clínica, tais funções 
sejam investigadas pelos médicos com perguntas específicas para que, se necessário, o fonoaudiólogo possa intervir.

Isso nos mostra como o tratamento terapêutico pode ser direcionado e preconizado quando se sabe como cada músculo desempenha sua função, seja ela de expressividade ou oral, para então, auxiliar durante o acompanhamento, na reabilitação destes pacientes e na evolução conforme a normalidade é retomada.

Um dos fatores para se prever o prognóstico da paralisia do NF é a sua gravidade. Atualmente, os sistemas de classificação House e Brackmann e Sunnybrook são os mais utilizados para graduar a doença de forma prática e imediata. Embora essas avaliações sejam realizadas por especialistas, foram demonstrados desacordos inter e intraobservadores. Nestes casos, a análise quantitativa e objetiva do grau seria a mais indicada para monitorar mudanças funcionais e planejar intervenções terapêuticas nesses pacientes (Katsumi et al., 2015).

Neste âmbito, a maioria das pesquisas realizadas para averiguar o movimento facial em 3D em casos de disfunção do NF utilizou métodos que empregavam pontos anatômicos de referência em ambos os lados da face, a fim de compará-los, buscar diferenças de assimetrias, velocidade de movimento e correlações entre determinada expressão facial e grau de comprometimento motor.

Em nosso estudo, a análise 3D mostrou diferença entre os GC e GPFP na razão de simetria entre os lados da face para todos os seis movimentos pesquisados, em seus eixos específicos e na junção das três coordenadas (3D). Assim como em nossos achados, Trotman et al. (2018) encontraram maiores índices de assimetria facial na comparação de sujeitos controles com os pacientes com paralisia de Bell, além de estes apresentarem menor mobilidade facial e menor velocidade de movimento. E mesmo quando diversas etiologias que acometem o NF foram agrupadas, a assimetria no movimento facial foi uma característica predominantemente demonstrada em comparação aos controles (Linstrom, 2002).

No que tangencia a disfunção do NF pré e pós-procedimentos reparadores, diferenças significantes foram encontradas na amplitude e 
assimetria dos movimentos faciais entre sujeitos controle e em pacientes com paralisia facial pós parotidectomia conservadora (Sforza et al., 2012a), na simetria pré e pós cirurgia de anastomose do nevo massetérico-facial (Sforza et al., 2012b), na assimetria do sorriso após reanimação facial com transferência do nervo massetérico (Sforza et al., 2014) e melhora na assimetria do sorriso, bem como na mobilidade da região perioral pré e pós reanimação facial (Sforza et al., 2015). Frey et al. (2008) demonstraram em seu experimento que a amplitude do sorriso dos pacientes com paralisia facial pesquisada por análise 3D aumentou significantemente após os procedimentos cirúrgicos.

Referente às variáveis analisadas neste estudo, investigamos se alguma expressão facial poderia ter maior influência na QV desses sujeitos. As expressões de surpresa (SP - próprio eixo e 3D), sorriso aberto (SA - próprio eixo e 3D) e sorriso fechado (SF - próprio eixo) foram as que se correlacionaram moderadamente ao subíndice de função física da QV, o que nos indica que o sorriso poderia sofrer influências pela paralisia facial, além de dificuldades maiores do controle motor oral para a mastigação, deglutição, fala e limpeza oral, principais ítens pesquisados pelo questionário de QV no subíndice de função física. Porém, as expressões faciais parecem não influenciar o âmbito social desses indivíduos, o que poderia ser justificado pela fase aguda da doença, fase esta em que as sequelas não se instalaram e o prognóstico é mais favorável.

Nossos achados mostram evidências de que é o terço inferior da face quem mais chama a atenção na paralisia de Bell, com correlações com gravidade da doença e influências na QV. van Veen, et al. (2018) sugeriram que a capacidade de sorrir possui maior importância entre os pacientes com paralisia facial, independente da fase da doença em que se encontram, pois a boca além de receber maior atenção, revela a presença da paralisia (Ishii et al., 2016; Su et al., 2018).

Devido à expressão facial ser uma parte essencial da comunicação humana e um dos principais meios de revelar emoções e fornecer pistas não verbais, o sorriso foi julgado como a expressão facial mais importante, que reflete positivamente tanto na pessoa sorrindo quanto no observador (Ishii et al., 2012), 
Mediante o exposto, temos a premissa de que durante o processo terapêutico, esta região deve ser melhor caracterizada, avaliada, acompanhada, tendo em vista suas influências na gravidade e na QV dos portadores de PFP, a fim de que seja preconizado a melhor forma de reabilitação.

No que se refere à gravidade da doença, esta apresentou correlação com algumas provas de mímica facial em seu eixo e na análise 3D, em especial, às provas de surpresa (SP), raiva (RV), sorriso aberto (SA) e sorriso fechado (SF). A prova de cheiro ruim (CR) apresentou apenas em seu próprio eixo. Assim como em nossos achados, Sawai et al. (2012) compararam o movimento facial de sorrir de pacientes com paralisia facial e controles e encontraram diferença entre os grupos em valores de assimetria, bem como, esses valores para o grupo com paralisia se correlacionaram com o gravidade da doença pela escala de House e Brackmann, dados reforçados por Sforza et al. (2012a) que referiram que a mobilidade facial diminui em pacientes com maior grau de acometimento.

Alguns métodos tridimensionais foram correlacionados com as escalas subjetivas. Apesar de metodologia diferente para a análise 3D, como um sistema de geração de imagens que buscou razão de simetria (Katsumi et al., 2015) e valores de velocidade e de aceleração (Zhao et al., 2016), os estudos demonstraram correlação dos movimentos faciais de portadores de PFP com a escala de House e Brackmann. Isso nos mostra como a avaliação subjetiva pode ser empregada na prática clínica de modo confiável.

Dentre as limitações deste estudo, destacamos que apesar de específico, o questionário adotado para estimar a QV desses pacientes não foi validado para a língua portuguesa, embora bastante utilizado na população brasileira (Toledo, 2007; Salles, Toledo e Ferreira, 2009; Sassi et al., 2011; Nascimento Remigio et al., 2015).

Ressaltamos também que as avaliações subjetivas utilizadas neste estudo, ainda que empregadas na mensuração da gravidade da paralisia facial, adotada como padrão universal e na quantificação do desempenho muscular, possuem menor concordância interavaliadores e requerem experiência para sua utilização. E neste contexto, a análise do movimento 3D fornece dados objetivos e quantitativos, além de não ser invasivo. Este método já bem explorado na literatura permite uma melhor investigação de diversas patologias, assim como 
em comparações pré e pós cirúrgicas (Ferrario e Sforza, 2007; Sforza at al., 2010a; 2010b; 2012a; 2012b; 2014; 2015; Sidequersky et al., 2016). 
7. CONCLUSÕES 


\section{CONCLUSÕES}

Baseado nos resultados do presente estudo foi possível concluir que os sujeitos com PFP adquirida, em fase aguda, apresentaram pior desempenho na mímica facial, tanto em análise perceptivo visual, quanto por análise optoeletrônica 3D, com altos índices de assimetria. Também demonstraram pior QV, para ambos os subíndices, função física e bem estar social, comparativamente à sujeitos controles.

Ainda em relação à $\mathrm{QV}$, as mulheres do grupo com PFP apresentaram piores índices no âmbito social comparadas aos homens e o aumento da idade foi um fator que influenciou na piora da função física, mas não do bem estar social.

O prejuízo no desempenho da mímica facial foi relacionado com a piora do grau da PF e com a pior $Q V$, relacionada à função física, mas não ao bem estar social. Os movimentos mais influenciados pela gravidade do comprometimento motor foram de surpresa, raiva, cheiro ruim, sorriso aberto e sorriso fechado. 
8. REFERÊNCIAS BIBLIOGRÁFICAS 


\section{REFERÊNCIAS BIBLIOGRÁFICAS ${ }^{1}$}

Arslan F, Gökgöz MC, Binar M, Aydemir E, Durmaz A. Anxiety, depression, and hopelessness in patients before and after treatment for peripheral facial paralysis. Ear Nose Throat J. 2018 Apr-May; 97(4-5): E1-E4.

Atolini Junior N, Jorge Junior JJ, Gignon VF, Kitice AT, Prado LSA, Santos VGW. Paralisia facial periférica: incidência das várias etiologias num ambulatório de atendimento terciário. Arq. Int. Otorrinolaringol. 2009; 13(2):167-71.

Bento RF, Miniti A, Marone SAM. Tratado de Otologia. São Paulo: EDUSP/Fundação Otorrinolaringologia/FAPESP; 1998. cap 11. p. 427-49.

Berg T, Jonsson L, Engström M. Agreement between the Sunnybrook, HouseBrackmann, and Yanagihara Facial Nerve Grading Systems in Bell's Palsy. Otol Neurotol. 2004 Dec; 25(6): 1020-6.

Berssenbrügge P, Berlin NF, Kebeck G, Runte C, Jung S, Kleinheinz J, Dirksen D. 2D and 3D analysis methods of facial asymmetry in comparison. J Craniomaxillofac Surg. 2014 Sep; 42(6): 327-34.

Beurskens CHG, Heymans PG. Mime therapy improves facial symmetry in people with long-term facial nerve paresis: A randomised controlled trial. Aust $\mathrm{J}$ Physiother. 2006; 52(3):177-83.

Beurskens CHG, Heymans PG. Positive Effects of Mime Therapy on Sequelae of Facial Paralysis: Stiffness, Lip Mobility, and Social and Physical Aspects of Facial Disability. Otol Neurotol. 2003 Jul; 24(4): 677-81

Bogart K, Tickle-Degnen L, Ambady N. Communicating Without the Face: Holistic Perception of Emotions of People With Facial Paralysis. Basic and Applied Social Psychology. 2014 Jul; 36(4): 309-20.

Caropreso VR. Paralisia facial bilateral: causas e tratamentos. São Paulo: Centro de Especialização em Fonoaudiologia Clínica; 2000.

Chevalier AM. Avaliação da função motora da face nas lesões periféricas e centrais. In: Lacôte M, Chevalier AM, Miranda A, Bleton JP, Stevenin P. Avaliação clínica da função muscular. São Paulo: Manole; 1987.

Cirpaciu D, Goanta CM, Cirpaciu MD. Recurrences of Bell's palsy. J Med Life. 2014;7(3):68-77.

Da Silveira AC, Daw JL Jr, Kusnoto B, Evans C, Cohen M. Craniofacial applications of three-dimensional laser surface scanning. J Craniofac Surg. 2003 Jul; 14(4): 449-56.

Díaz-Aristizabal U, Valdés-Vilches M, Fernández-Ferreras TR, Calero-Muñoz E, Bienzobas-Allué E, Moracén-Naranjo T. Correlations between impairment, psychological distress, disability, and quality of life in peripheral facial palsy. Neurologia. 2017 May 23.

Dib GC, Kosugi EM, Antunes ML. Paralisia facial periférica. Rev Bras Med. 2004(61):110-7.

${ }^{1}$ Segundo Estilo Vancouver 
Dong SH, Jung AR, Jung J, Jung SY, Byun JY, Park MS, Kim SH, Yeo SG. Recurrent Bell's palsy. Clin Otolaryngol. 2019 Jan

Farkas LG. Examination, In: Farkas LG. Anthropometry of the Head and Face. 2ed. New York. Raven Press; 1994.

Fattah A, Gurusinghe A, Gavilan J, Hadlock TA, Marcus JR, Marres H, Nduka CC, Slattery WH, Snyder-Warwick AK; Sir Charles Bell Society. Facial nerve grading scales: systematic review of the literature and suggestion for uniformity. Plast Reconstr Surg 2015 Feb;135(2): 569-79.

Fernandes AMF, Lazarini PR. Anatomia do Nervo Facial. In: Lazarini PR; Fouquet ML. Paralisia facial: avaliação, tratamento, reabilitação. São Paulo: Lovise; 2006. cap 1. p. 01-10.

Ferrario VF, Sforza C. Anatomy of emotion: a 3D study of facial mimicry. Eur J Histochem. 2007; 51(1): 45-52.

Finsterer J. Management of peripheral facial nerve palsy. Eur Arch Otorhinolaryngol. $2008 \mathrm{Jul} ; 265(7)$ : 743-52.

Fisch U. Surgery for Bell's Palsy. Arch Otolaryngol. 1981 Jan; 107(1): 1-11.

Fonseca ACO. Avaliação Clínica da Paralisia Facial Periférica. In: Bento RF, Salomone R, Fonseca ACO, Faria JCM, Martins RS, Goffi-Gomez MVS. Tratado de Paralisia Facial: Fundamentos Teóricos - Aplicação Prática. Rio de Janeiro, 2018. p. 35-39.

Fonseca KM, Mourão AM, Motta AR, Vicente LC. Scales of degree of facial paralysis: analysis of agreement. Braz J Otorhinolaryngol. 2015 May/Jun; 81(3): 288-93.

Fouquet ML. Atuação Fonoaudiológica nas Paralisias Faciais. In: Barros APB, Arakawa L, Tonini MD, Carvalho VA (org.). Fonoaudiologia em cancerologia. Fundação Oncocentro de São Paulo, Comitê de Fonoaudiologia em Cancerologia. São Paulo: FOSP. 2000. p.99-104.

Fourie Z, Damstra J, Gerrits PO, Ren Y. Evaluation of anthropometric accuracy and reliability using different three-dimensional scanning systems. Forensic Sci Int. 2011 Apr 15; 207(1-3): 127-34.

Franzke P, Bitsch A, Walther M, Schiffner R, Rupprecht S, Rasche M, Volk GF, Witte OW, Schlattmann P, Guntinas-Lichius O, Hagemann G,Schwab M, Rakers F. Weather, Weather Changes and the Risk of Bell's Palsy: A Multicenter CaseCrossover Study. Neuroepidemiology. 2018; 51(3-4): 207-15.

Frey $M$, Michaelidou M, Tzou CH, Pona I, Mittlböck M, Gerber H, Stüssi E. Three-dimensional video analysis of the paralyzed face reanimated by cross-face nerve grafting and free gracilis muscle transplantation: quantification of the functional outcome. Plast Reconstr Surg. 2008 Dec; 122(6): 1709-22.

Frey M, Tzou CH, Michaelidou M, Pona I, Hold A, Placheta E, Kitzinger HB. 3D Video Analysis of Facial Movements. Facial Plast Surg Clin North Am. 2011(19):639-46.

Finsterer J. Management of peripheral facial nerve palsy. Eur Arch Otorhinolaryngol. 2008 Jul; 265(7): 743-52. 
Frith C. Role of facial expressions in social interactions. Philos Trans R Soc Lond B biol Sci. 2009 (364):3453-8.

Fu X, Tang L, Wang C, Li M, Wu H, Li J, Ma Q, Yang W. A Network MetaAnalysis to Compare the Efficacy of Steroid and Antiviral Medications for Facial Paralysis from Bell's Palsy. Pain Physician.2018 Nov; 21(6): 559-69.

Gillman GS, Schaitkin BM, May M, Klein SR. Bell's palsy in pregnancy: a study of recovery outcomes. Otolaryngol Head Neck Surg 2002;126:26-30.

Giovanoli P, Tzou $\mathrm{CH}$, Ploner M, Frey M. Three-dimensional video-analysis of facial movements in healthy volunteers. Br J Plast Surg. 2003 Oct; 56(7): 644-52.

Gross MM, Trotman CA, Moffatt KS. A comparison of three-dimensional and twodimensional analyses of facial motion. Angle Orthod. 1996; 66(3): 189-94.

Györi E, Przestrzelski C, Pona I, Hagmann M, Rath T, Radtke C,Tzou CJ. Quality of life and functional assessment of facial palsy patients: A questionnaire study. Int J Surg. 2018 Jul; 55: 92-7.

Hilsinger RL Jr, Adour KK, Doty HE. Idiopathic facial paralysis, pregnancy, and the menstrual cycle. Ann Otol Rhinol Laryngol. 1975 Jul-Aug; 84(4): 433-42.

Ho AL, Scott AM, Klassen AF, Cano SJ, Pusic AL, Van Laeken N. Measuring quality of life and patient satisfaction in facial paralysis patients. Plast Reconstr Surg. 2012 Jul; 130(1): 91-99.

Holland NJ, Weiner M. Recent developments in Bell's palsy. BMJ. 2004; 329:553-7.

Hontanilla B, Aubá C. Automatic three-dimensional quantitative analysis for evaluation of facial movement. J Plast Reconstr Aesthet Surg. 2008; 61(1): 1830.

House JW, Brackmann DE. Facial nerve grading system. Otolaryngol Head Neck Surg. 1985 Apr; 93(2): 146-7.

Huffman MD; Baker RS; Stava MW; Chuke JC; Rouholiman BR; Porter JD. Kinematic analysis of eyelid movements in patients recovering from unilateral facial nerve palsy. Neurology. 1996(46):1079-85.

Ishii L, Dey J, Boahene KD, Byrne PJ, Ishii M. The social distraction of facial paralysis: objective measurement of social attention using eye-tracking. Laryngoscope. 2016 Feb; 126(2): 334-39.

Ishii L, Godoy A, Encarnacion CO, Byrne PJ, Boahene KD, Ishii M. Not just another face in the crowd: Society's perceptions of facial paralysis. Laryngoscope. 2012 Mar; 122(3): 533-538.

Ishii LE, Godoy A, Encarnacion CO, Byrne PJ, Boahene KD, Ishii M. What faces reveal: impaired affect display in facial paralysis. Laryngoscope. 2011 May; 121:1138-43.

Ishii LE, Nellis JC, Boahene KD, Byrne $\mathrm{P}$, Ishii $\mathrm{M}$. The importance and psychology of facial expression. Otolaryngol. Clin. North Amer. 2018 Dec; 51(6): 1011-17. 
Joe PS, Ito Y, Shih AM, Oestenstad RK, Lungu CT. Comparison of a novel surface laser scanning anthropometric technique to traditional methods for facial parameter measurements. J Occup Environ Hyg. 2012; 9(2): 81-8.

Johnson PC, Brown H, Kuzon WM Jr, Balliet R, Garrison JL, Campbell J. Simultaneous quantitation of facial movements: the maximal static response assay of facial nerve function. Ann Plast Surg. $1994 \mathrm{Feb}$; 32(2): 171-9.

Kahn JB, Gliklich RE, Boyev KP, Stewart MG, Metson RB, McKenna MJ. Validation of a patient-graded instrument for facial nerve paralysis: the FaCE scale. Laryngoscope. 2001 Mar; 111(3): 387-98.

Kato $\mathrm{Y}$, Kamo H, Kobayashi A, Abe S, Okada-Ogawa A, Noma N, Kukimoto N, Omori H, Nakazato H, Kishi H, Ikeda M, Imamura Y. Quantitative evaluation of oral function in acute and recovery phase of idiopathic facial palsy; a preliminary controlled study. Clin Otolaryngol. 2013 Jun; 38(3): 231-6.

Katsumi S, Esaki S, Hattori K, Yamano K, Umezaki T, Murakami S. Quantitative analysis of facial palsy using a three-dimensional facial motion measurement system. Auris Nasus Larynx. 2015 Aug; 42(4): 275-83.

Kim JH, Fisher LM, Reder L, Hapner ER, Pepper JP. Speech and communicative participation in patients with facial paralysis. JAMA Otolaryngol Head Neck surg. 2018 Aug; 144(8): 686-93.

Kleiss IJ, Hohman MH, Susarla SM, Marres HA, Hadlock TA. Health-related quality of life in 794 patients with a peripheral facial palsy using the FaCE Scale: a retrospective cohort study. Clin Otolaryngol. 2015 Dec; 40(6):651-6.

Lazarini PR, Mitre EI, Szajubok A. Paralisia Facial Periférica. In: Campos CAH e Olival Costa HOO (Org.). Tratado de Otorrinolaringologia. São Paulo: Roca 2, 2002. cap 38. v 2. p. 395-415.

Lee JG, Jung SJ, Lee HJ, Seo JH, Choi YJ, Bae HS, Park JT, Kim HJ. Quantitative anatomical analysis of facial expression using a 3D motion capture system: Application to cosmetic surgery and facial recognition technology. Clin Anat. 2015 Sep; 28(6): 735-44.

Leong SC, Lesser TH. A national survey of facial paralysis on the quality of life of patients with acoustic neuroma. Otol Neurotol. 2015 Mar; 36(3): 503-9.

Li MK, Niles N, Gore S, Ebrahimi A, McGuinness J, Clark JR. Social perception of morbidity in facial nerve paralysis. Head Neck 2016 May; 38(8): 1158-63.

Linstrom CJ. Objective facial motion analysis in patients with facial nerve dysfunction. Laryngoscope. 2002; 112(7 Pt 1) 1129-47.

Lowney CJ, Hsung TC, Morris DO, Khambay BS. Quantitative dynamic analysis of the nasolabial complex using 3D motion capture: A normative data set. J Plast Reconstr Aesthet Surg. 2018 Sep;71(9):1332-45.

Luijmes RE, Pouwels S, Beurskens CHG, Kleiss IJ, Siemann I, Ingels KJ. Quality of life before and after different treatment modalities in peripheral facial palsy: a systematic review. Laryngoscope. 2017 May; 127(5):1044-51. 
Luijmes RE, Pouwels S, Monstrey SJ, Ingels KJAO, Beurkens CHG. The forgotten aspects of the quality of life of significant others of patients with a peripheral facial palsy. J Plast Reconstr Aesthet Surg. 2018 Jul; 71(7):1094-5.

McCaul JA, Cascarini L, Godden D, Coombes D, Brennan PA, Kerawala CJ. Evidence based management of Bell's palsy. Br J Oral Maxillofac Surg. 2014 May; 52:387-91.

Minitri A, Bento RF, Butugan O. Paralisia Facial Periférica. In: Minitri A, Bento RF, Butugan O. Otorrinolaringologia: Clínica e Cirúrgica. São Paulo: Atheneu; 2000. cap 30. p. 355-78.

Mitre El, Giancoli SM e Lazarini PR. Avaliação Clínica na Paralisia Facial Periférica. In: Lazarini PR; Fouquet ML. Paralisia facial: avaliação, tratamento, reabilitação. São Paulo: Lovise, 2006. cap 4. p. 33-52.

Movérare T, Lohmander A, Hultcrantz M, Sjögreen L. Peripheral facial palsy: Speech, communication and oral motor function. Eur Ann Otorhinolaryngol Head Neck Dis. 2017 Feb; 134(1): 27-31.

Mun SJ, Park KT, Kim Y, Park JH, Kim YH. Characteristics of the perception for unilateral facial nerve palsy.Eur Arch Otorhinolaryngol. 2015 Nov; 272(11): 32539.

Nakamura K, Toda N, Sakamaki K, Kashima K, Takeda N. Biofeedback rehabilitation for prevention of synkinesis after facial palsy. Otolaryngol Head Neck Surg. 2003 Apr; 128(4): 539-43.

Nascimento Remigio AF, Salles AG, de Faria JC, Ferreira MC. Comparison of the Efficacy of OnabotulinumtoxinA and AbobotulinumtoxinA at the 1:3 Conversion Ratio for the Treatment of Asymmetry after Long-Term Facial Paralysis. Plast Reconstr Surg. 2015 Jan; 135(1): 239-49.

Nellis JC, Ishii M, Byrne PJ, Boahene KDO, Dey JK, Ishii LE. Association among facial paralysis, depression, and quality of life in facial plastic surgery patients. JAMA Facial Plast Surg. 2016 May; 19(3): 190-6.

$\mathrm{Ng} \mathrm{JH}$, Ngo RY. The use of the facial clinimetric evaluation scale as a patientbased grading system in Bell's palsy. Laryngoscope. 2013 May; 123(5): 125660.

Ordahan B, Karahan A. Role of low-level laser therapy added to facial expression exercises in patients with idiopathic facial (Bell's) palsy. Lasers Med Sci. 2017 May; 32(4): 931-936.

Owusu JA, Stewart CM, Boahene K. Facial Nerve Paralysis. Med Clin North Am. 2018 Nov; 102(6):1135-1143.

Pecket P, Schattner A. Concurrent Bell's palsy and diabetes mellitus: a diabetic mononeuropathy? J Neurol Neurosurg Psychiatry. 1982 Jul; 45(7):652-5.

Pereira LM, Obara K, Dias JM, Menacho MO, Lavado EL, Cardoso JR. Facial exercise therapy for facial palsy: systematic review and meta-analysis. Clin Rehabil. 2011 Jul; 25(7): 649-58.

Popat H, Henley E, Richmond S, Benedikt L, Marshall D, Rosin PL. A comparison of the reproducibility of verbal and nonverbal facial gestures using three- 
dimensional motion analysis. Otolaryngol Head Neck Surg. 2010 Jun; (142): 86772.

Popat H, Richmond S, Benedikt L, Marshall D, Rosin PL. Quantitative analysis of facial movement - a review of three-dimensional imaging techniques. Comput Med Imaging Graph. 2009 Jul; 33(5): 377-83.

Popat H, Richmond S, Playle R, Marshall D, Rosin P, Cosker D. Threedimensional motion analysis - an exploratory study. Part 1: assessment of facial movement. Orthod Craniofac Res. 2008a Nov; 11(4): 216-23.

Popat H, Richmond S, Playle R, Marshall D, Rosin P, Cosker D. Threedimensional motion analysis - an exploratory study. Part 2: assessment of facial movement. Orthod Craniofac Res. 2008b Nov; 11(4): 224-8.

Popat H, Zhurov Al, Toma AM, Richmond S, Marshall D, Rosin PL. Statistical modelling of lip movement in the clinical context. Orthod Craniofac Res. 2012 May; 15(2):92-102.

Prats-Golczer VE, Gonzalez-Cardero E, Exposito-Tirado JA, Montes-Latorre E, Gonzalez-Perez LM, Infante-Cossio P. Impact of dysfunction of the facial nerve after superficial parotidectomy: a prospective study. $\mathrm{Br} \mathrm{J}$ Oral Maxillofac Surg. 2017 Oct; 55(8): 798-802.

Ramieri GA, Spada MC, Nasi A, Tavolaccini A, Vezzetti E, Tornincasa S, Bianchi $\mathrm{SD}$, Verzé L. Reconstruction of facial morphology from laser scanned data. Part I: reliability of the technique. Dentomaxillofac Radiol 2006; 35: 158-64.

Reich SG. Bell's Palsy. Continuum (Minneap Minn). 2017 Apr; 23(2):447-466.

Roob G, Fazekas F, Hartung HP. Peripheral facial palsy: Etiology, diagnosis and treatment. Eur Neurol 1999;41:3-9.

Ross B, Nedzelski JM, McLean JA. Efficacy of feedback training in long-standing facial nerve paresis. Laryngoscope. 1991 Jul; 101(7) 744-50.

Ross BG, Fradet G, Nedzelski JM. Development of a sensitive clinical facial grading system. Otolaryngol Head Neck Surg. 1996 Mar; 114(3): 380-6.

Salgado MD, Curtiss S, Tollefson TT. Evaluating symmetry and facial motion using 3D videography. Facial Plast Surg Clin North Am. 2010(18):351-6.

Salles AG, Toledo PN, Ferreira MC. Botulinum toxin injection in long-standing facial paralysis patients: improvement of facial symmetry observed up to 6 months. Aesthetic Plast Surg. 2009 Jul; 33(4): 582-90.

Santos DA. Aspectos Psicológicos na Paralisia Facial Periférica. In: Lazarini PR; Fouquet ML. Paralisia facial: avaliação, tratamento, reabilitação. São Paulo: Lovise, 2006. cap 19. p. 181-84.

Sassi FC, Toledo PN, Mangilli LD, Alonso N, Andrade CRF. Correlação entre eletromiografia e índice de inabilidade facial em pacientes com paralisia facial de longa duração: implicações para o resultado de tratamentos. Rev. Bras. Cir. Plást. 2011 Dec; 26(4): 596-01.

Sawyer AR, See M, Nduka C. Quantitative analysis of normal smile with 3D stereophotogrammetry--an aid to facial reanimation. J Plast Reconstr Aesthet Surg. 2010 Jan; 63(1):65-72. 
Segal B, Zompa I, Danys I, Black M, Shapiro M, Melmed C, Arthurs B. Symmetry and synkinesis during rehabilitation of unilateral facial paralysis. J Otolaryngol. 1995 Jun; 24(3): 143-8.

Schirm J, Mulkens PSJZ. Bell's palsy and herpes simplex virus. APMIS 1997 Nov;105:815-23.

Sforza C, Frigerio A, Mapelli A, Mandelli F, Sidequersky FV, Colombo C, Ferrario VF, Bigliolo F. Facial movement before and after masseteric-facial nerves anastomosis: a three-dimensional optoelectronic pilot study. J Craniomaxillofac Surg. 2012b(40):473-9.

Sforza C, Frigerio A, Mapelli A, Tarabbia F, Annon I, Colombo V, Latiff M, Pimenta Ferreira CL, Rabbiosi D, Sidequersky FV, Zago M, Biglioli F. Doublepowered free gracilis muscle transfer for smile reanimation: a longitudinal optoelectronic study. J Plast Reconstr Aesthet Surg. 2015(68):930-9.

Sforza C, Galante D, Shirai YF, Ferrario VF. A three-dimensional study of facial mimicry in healthy young adults. J Cranio-maxillofac Surg. 2010a(38):409-15.

Sforza C, Guzzo M, Mapelli A, Ibba TM, Scaramellini G, Ferrario VF. Facial mimicry after conservative parotidectomy: a three-dimensional optoelectronic study. Int. J. Oral Maxillofac. Surg. 2012a(41):986-93.

Sforza C, Mapelli A, Galante D, Moriconi S, Ibba TM, Ferraro L, Ferrario VF. The effect of age and sex on facial mimicry: a three-dimensional study in healthy adults. Int. J. Oral Maxillofac. Surg. 2010b(39): 990-99.

Sforza C, Tarabbia F, Mapelli A, Colombo V, Sidequersky FV, Rabbiosi D, Annoni I, Biglioli F. Facial reanimation with masseteric to facial nerve transfer: A three-dimensional longitudinal quantitative evaluation. J Plast Reconstr Aesthet Surg. 2014 (67):1378-86.

Sforza C, Ulaj E, Gibelli DM, Allevi F, Pucciarelli V, Tarabbia F, Ciprandi D, Dell'Aversana Orabona G, Dolci C, Biglioli F. Three-dimensional superimposition for patients with facial palsy: an innovative method for assessing the success of facial reanimation procedures. Br J Oral Maxillofac Surg. 2018 Jan; 56(1): 3-7.

Shaw WC. The influence of children's dentofacial appearance on their social attractiveness as judged by peers and lay adults. Am J Orthod. 1981 (79):399-15.

Sidequersky FV, Mapelli A, Annoni I, Zago M, De Felício CM, Sforza C. Threedimensional motion analysis of facial movement during verbal and nonverbal expressions in healthy subjects. Clin Anat. 2016 Nov;29(8):991-7.

Sidequersky FV, Verzé L, Mapelli A, Ramieri GA, Sforza C. Quantification of facial movements by optical instruments: surface laser scanning and optoelectronic three-dimensional motion analyzer. J Craniofac Surg. 2014 Jan; 25(1): 65-70.

Su P, Ishii LE, Nellis J, Dey J, Bater KL, Byrne PJ, Boahene KDO, Ishii M. Societal identification of facial paralysis and paralysis location. JAMA Facial Plast Surg $2018 \mathrm{Jul} /$ Aug; 20(4): 272-6.

Toledo, Paula Nunes. Efeito da terapia miofuncional em pacientes com paralisia facial de longa duração associada à aplicação de toxina botulínica. São Paulo. 
Tese [Doutorado em Cirurgia Plástica] - Faculdade de Medicina da Universidade de São Paulo; 2007.

Trotman CA, Faraway J, Hadlock T, Banks C, Jowett N, Jung HJ. Facial Softtissue Mobility: Baseline Dynamics of Patients with Unilateral Facial Paralysis. Plast Reconstr Surg Glob Open. 2018 Oct 4; 6(10): 1-12.

Vakharia K, Vakharia K. Bell's Palsy. Facial Plast Surg Clin North Am. 2016 Feb;24(1):1-10.

VanSwearingen JM, Brach JS. The Facial Disability Index: reliability and validity of a disability assessment instrument for disorders of the facial neuromuscular system. Phys Ther. 1996 Dec; 76(12): 1288-98, 1298-300.

van Veen MM, Tavares-Brito J, van Veen BM, Dusseldorp JR, Werker PMN, Dijkstra PU, Hadlock TA. Association of Regional Facial Dysfunction With Facial Palsy-Related Quality of Life. JAMA Facial Plast Surg. 2018 Aug.

Veiga JCE. Paralisia Facial Central. In: Lazarini PR; Fouquet ML. Paralisia facial: avaliação, tratamento, reabilitação. São Paulo: Lovise, 2006. cap 9. p. 109-14.

Verzé L, Bianchi FA, Schellino E, Ramieri G. Soft tissue changes after orthodontic surgical correction of jaws asymmetry evaluated by threedimensional surface laser scanner. J Craniofac Surg. 2012 Sep; 23(5): 1448-52.

Verzé L, Nasi A, Quaranta F, Vasino V, Prini V, Ramieri G. Quantification of facial movements by surface laser scanning. J Craniofac Surg. 2011 Jan; 22(1): 60-5.

Vianna M, Adams M, Schachern P, Lazarini PR, Paparella MM, Cureoglu S. Differences in the diameter of facial nerve and facial canal in Bell's palsy - a 3dimensional temporal bone study. Otol Neurotol. 2014 Mar; 35:514-8.

Vimercati SL, Rigoldi C, Albertini G, Crivellini M, Galli M. Quantitative evaluation of facial movement and morphology. Ann Otol Rhinol Laryngol. 2012 Apr; 121(4): 246-52.

Volk GF, Granitzka T, Kreysa H, Klingner CM, Guntinas-Lichius O. Nonmotor disabilities in patients with facial palsy measured by patient-reported outcome measures. Laryngoscope. 2016 Jul; 126(7): 1516-23.

Weenden JC, Trotman CA, Faraway JJ. Three dimensional analysis of facial movement in normal adults: influence of sex and facial shape. Angle Orthod. 2001 Apr; 71(2): 132-40.

Wenceslau LGC, Sassi FC, Magnani DM, Andrade CRF. Paralisia facial periférica: atividade muscular em diferentes momentos da doença. CoDAS. 2016; 28(1):3-9.

Zaki MA, Elkholy SH, Abokrysha NT, Khalil AS, Nawito AM, Magharef NW, Kishk NA. Prognosis of Bell Palsy: A Clinical, Neurophysiological, and Ultrasound Study. J Clin Neurophysiol. 2018 Nov; 35(6): 468-73.

Zhao Y, Feng G, Gao Z. Advances in diagnosis and non-surgical treatment of Bell's palsy. J Otol. 2015 Jun;10(1):7-12. 


\section{APÊNDICE A}

\section{TERMO DE CONSENTIMENTO LIVRE E ESCLARECIDO}

\section{Grupo Estudo}

Eu, Monize Vilela, o convido a participar da pesquisa "BIOMECÂNICA OROFACIAL NA PARALISIA FACIAL PERIFÉRICA". Caso concorde, eu farei algumas perguntas para saber se $\circ \mathrm{Sr}$. (a) se encontra nos critérios para ser incluído (a) na pesquisa. Informo que esse Termo de Consentimento Livre e Esclarecido terá duas vias e que uma ficará com o Sr. (a) e a outra arquivada comigo, que sou a pesquisadora responsável. E que as pesquisadoras (eu e minha orientadora) manterão sigilo sobre a sua participação na pesquisa, ou seja, o seu nome não será divulgado.

\section{DO QUE SE TRATA A PESQUISA?}

Este estudo tem como objetivo investigar a biomecânica orofacial (que é o estudo do movimento do rosto, assim como a posição, o deslocamento, a velocidade e a aceleração de suas estruturas) em diferentes casos de paralisia facial periférica adquirida (no qual o nervo facial foi lesado) e comparar à um grupo de pessoas que não tem esse problema. Serão realizados vários exames para verificar como se comporta os músculos do seu rosto e as funções de mastigação, deglutição (engolir) e respiração. Também será verificado se existe relação das alterações dos músculos da face com sua qualidade de vida (verificadas por meio de perguntas que serão explicadas a seguir).

\section{COMO SERÁ REALIZADA? E ONDE?}

Será feito um questionário com perguntas para entendermos melhor como aconteceu a paralisia fácil, há quanto tempo ela ocorreu, se houve um motivo, se utilizou medicamentos, etc. Será feito também uma avaliação na sua boca e na face, verificando como estão suas estruturas como dentes, língua, lábios, 
bochechas, mandíbula; sua aparência e os movimentos dessas estruturas. Essa avaliação será filmada para poder ser melhor analisada depois e o resultado dessa avaliação será anotado em uma ficha. Um outro questionário será realizado para avaliarmos se o (a) Sr. (a) tem queixas na articulação temporomandibular (onde articula a mandíbula no crânio, perto do ouvido) em diferentes momentos do dia e em diferentes situações e por meio de palpação (tocar firme com os dedos) nos músculos da face. Além disso, será feito um exame com movimentos faciais a fim de definirmos o grau da paralisia facial (o quanto está alterado) e o (a) Sr. (a) responderá algumas perguntas sobre suas atividades no dia a dia, assim como dificuldades relacionadas a sua qualidade de vida, devido a paralisia facial.

Em seguida serão feitos os exames com os equipamentos. O Sr. (a) será submetido a um exame que mede quanta força os lábios e as bochechas possuem, bem como a força de sua mordida dos dentes do fundo.

Para isso será posicionado um instrumento entre os seus lábios, no qual o Sr. (a) deverá apertar os lábios o máximo que conseguir. A força das bochechas será avaliada pelo mesmo equipamento, no qual será posicionado em sua bochecha dentro da boca e será solicitado que o Sr. (a) faça força para apertar o equipamento. Para avaliar a sua força de mordida dos dentes será solicitado que o Sr. (a) realize a força máxima num equipamento posicionado nos dentes do fundo. Cada medida será feita três vezes com descanso entre cada lado.

O Sr. (a) será submetido a um exame que fará uma "cópia" do seu rosto que aparecerá como uma foto no computador, de frente e dos lados direito e esquerdo. Para tal, o Sr. (a) será convidado a ficar em pé, com os olhos fechados e o avaliador irá deslizar um equipamento com laser na direção da sua face, sem encostar, causar dor ou desconforto, em um tempo total de aproximadamente 10 minutos.

Será também realizado uma prova em que pequenas bolinhas luminosas serão coladas em alguns pontos do seu rosto e câmeras de vídeo especiais captarão os movimentos faciais que o Sr. (a) realizará após minha instrução, como movimentos de levantar as sobrancelhas, sorrir, piscar, etc.

Todos os exames serão realizados no mesmo lugar, no Laboratório de Fonoaudiologia, na casa de número 18 da Rua das Paineiras, dentro do Campus 
da USP. Para isso o Sr. (a) receberá um mapa e explicações de como chegar, caso ainda não saiba.

\section{OS EXAMES SÃO DESCONFORTÁVEIS OU GERAM RISCOS?}

Toda pesquisa com seres humanos envolve risco em tipos e gradações variados. Devem ser analisadas possibilidades de danos imediatos ou posteriores, no plano individual ou coletivo (Resolução no 466, de 12 de dezembro de 2012).

Os exames propostos não causam nenhum prejuízo. Mas, existe um risco mínimo de o Sr. (a), por algum motivo que não conhecemos, sentir algum tipo de dor, desconforto ou cansaço nos músculos do rosto durante a realização dos exames. Caso isso aconteça, as examinadoras vão parar de fazer as avaliações. Depois, elas verão se é possível continuar os exames ou se serão agendados para outro dia ou ainda, se não serão mais realizados. As pesquisadoras manterão sigilo sobre a sua identidade e o Sr. (a) será esclarecido quanto aos procedimentos realizados e informado sobre os resultados que vamos ter com a pesquisa, sendo que tem total garantia de acesso aos resultados da pesquisa. $\mathrm{E}$ a qualquer momento, o Sr. (a) poderá desistir que esses dados sejam utilizados na presente pesquisa. Portanto, as pesquisadoras tomarão todos os cuidados possíveis em manter o sigilo a respeito da sua identidade e participação no estudo. Entretanto, caso o Sr. (a) sinta-se lesado, é de seu direito solicitar indenização, conforme legislação vigente.

\section{O PARTICIPANTE TERÁ GASTOS OU DESPESAS?}

Caso o Sr. (a) tenha que se locomover até o Laboratório de Fonoaudiologia para realização exclusiva dos exames da pesquisa, nós nos comprometemos a dar assistência e fornecer recursos para o transporte (valor em reais equivalente às passagens de ida de volta, seja de dentro de Ribeirão Preto ou de alguma cidade vizinha) e também quanto ao lanche que poderá ser disponibilizado antes ou após a realização dos exames, conforme solicitada e afirmada a necessidade. 
Nada será cobrado, assim como o Sr.(a) também não receberá qualquer benefício financeiro. As pesquisadoras se comprometem a prestar assistência integral no decorrer da pesquisa, se algum problema decorrer desta. A indenização, a título de cobertura material, para reparação de danos imediatos ou tardios, decorrentes da sua participação na pesquisa, caso ocorra, será realizada pelas pesquisadoras, não cabendo ao Hospital das Clínicas de Ribeirão Preto qualquer responsabilidade quanto aos referidos pagamentos.

\section{A PESQUISA TRARÁ ALGUM BENEFÍCIO PARA O PARTICIPANTE?}

Sim, os exames realizados contribuirão para identificar as alterações presentes nos músculos da face e assim facilitará o plano de tratamento da Fonoaudiologia, que requer exercícios para a melhora da expressão facial e das funções de mastigação, deglutição e fala, caso seja indicado para o seu caso. Serão feitos exames de rotina do serviço de Fonoaudiologia (como a avaliação clínica) e outros exames instrumentais complementares, que não são feitos na rotina do mesmo serviço.

\section{O QUE ACONTECE COM QUEM NÃO PARTICIPA DA PESQUISA?}

A sua participação no estudo é voluntária, não acarretando absolutamente nada ao Sr. (a) caso não aceite participar. O Sr. (a) tem a liberdade de se recusar a participar ou poderá interromper a pesquisa a qualquer momento, sem qualquer risco de prejuízos ou penalidades. Como explicado acima, caso não participe da pesquisa, fará o exame de rotina (avaliação clínica orofacial) no serviço de Fonoaudiologia, sem fazer os exames complementares, sem interferência no seu tratamento no hospital.

Concordando em participar da pesquisa o Sr. (a) assinará o Termo de Consentimento Livre e Esclarecido, o qual consta os dados das Pesquisadoras Responsáveis, para caso necessite de maiores informações, ou por qualquer outra necessidade e poderá entrar em contato a qualquer momento, assim como poderá entrar em contato com o Comitê de Ética em pesquisa do Hospital das Clínicas da Faculdade de Medicina de Ribeirão Preto caso tenha alguma 
reclamação, recurso ou dúvida, pelo telefone (16) 3602-2228. Dados da pesquisadora responsável para eventuais necessidades:

Fga. Monize Vilela

End: Av. Bandeirantes, 3900, Monte Alegre, Ribeirão Preto, Cep: 14.049.900

Tel: (16) 3315-0592 (Laboratório de Fonoaudiologia).

Email: monize.vilela@hotmail.com

Pesquisadora: Participante:

Data: Data: 


\section{APÊNDICE B}

\section{TERMO DE CONSENTIMENTO LIVRE E ESCLARECIDO}

\section{Grupo Controle}

Eu, Monize Vilela, o convido a participar da pesquisa "BIOMECÂNICA OROFACIAL NA PARALISIA FACIAL PERIFÉRICA". Caso concorde, eu farei algumas perguntas para saber se $\circ \mathrm{Sr}$. (a) se encontra nos critérios para ser incluído (a) na pesquisa. Informo que esse Termo de Consentimento Livre e Esclarecido terá duas vias e que uma ficará com o Sr. (a) e a outra arquivada comigo, que sou a pesquisadora responsável. E que as pesquisadoras (eu e minha orientadora) manterão sigilo sobre a sua participação na pesquisa, ou seja, o seu nome não será divulgado.

\section{DO QUE SE TRATA A PESQUISA?}

Este estudo tem como objetivo investigar a biomecânica orofacial (que é o estudo do movimento do rosto, assim como a posição, o deslocamento, a velocidade e a aceleração de suas estruturas) em diferentes casos de paralisia facial periférica adquirida (no qual o nervo facial foi lesado) e comparar à um grupo de pessoas que não tem esse problema (no qual o Sr. (a) encaixa-se neste grupo). Serão realizados vários exames para verificar como se comporta os músculos do seu rosto e as funções de mastigação, deglutição (engolir) e respiração. Também será verificado se existe relação das alterações dos músculos da face com sua qualidade de vida (verificadas por meio de perguntas que serão explicadas a seguir).

\section{COMO SERÁ REALIZADA? E ONDE?}

O Sr. (a) será questionado se usa dentadura total ou parcial superior e/ou inferior, e se possui alguma alteração nos músculos da face. Será feito também uma avaliação na sua boca e na face, verificando como estão suas estruturas 
como dentes, língua, lábios, bochechas, mandíbula; sua aparência e os movimentos dessas estruturas. Essa avaliação será filmada para poder ser melhor analisada depois e o resultado dessa avaliação será anotado em uma ficha. Um outro questionário será realizado para avaliarmos se o (a) Sr. (a) tem queixas na articulação temporomandibular (onde articula a mandíbula no crânio, perto do ouvido) em diferentes momentos do dia e em diferentes situações e por meio de palpação (tocar firme com os dedos) nos músculos da face. Além disso, será feito um exame com movimentos faciais a fim de definirmos o grau da paralisia facial (o quanto está alterado) e o (a) Sr. (a) responderá algumas perguntas sobre suas atividades no dia a dia, assim como dificuldades relacionadas a sua qualidade de vida.

Em seguida serão feitos os exames com os equipamentos. O Sr. (a) será submetido a um exame que mede quanta força os lábios e as bochechas possuem, bem como a força de sua mordida dos dentes do fundo.

Para isso será posicionado um instrumento entre os seus lábios, no qual o Sr. (a) deverá apertar os lábios o máximo que conseguir. A força das bochechas será avaliada pelo mesmo equipamento, no qual será posicionado em sua bochecha dentro da boca e será solicitado que o Sr. (a) faça força para apertar o equipamento. Para avaliar a sua força de mordida dos dentes será solicitado que o Sr. (a) realize a força máxima num equipamento posicionado nos dentes do fundo. Cada medida será feita três vezes com descanso entre cada lado.

O Sr. (a) será submetido a um exame que fará uma "cópia" do seu rosto que aparecerá como uma foto no computador, de frente e dos lados direito e esquerdo. Para tal, o Sr. (a) será convidado a ficar em pé, com os olhos fechados e o avaliador irá deslizar um equipamento com laser na direção da sua face, sem encostar, causar dor ou desconforto, em um tempo total de aproximadamente 10 minutos.

Será também realizado uma prova em que pequenas bolinhas luminosas serão coladas em alguns pontos do seu rosto e câmeras de vídeo especiais captarão os movimentos faciais que o Sr. (a) realizará após minha instrução, como movimentos de levantar as sobrancelhas, sorrir, piscar, etc.

Todos os exames serão realizados no mesmo lugar, no Laboratório de Fonoaudiologia, na casa de número 18 da Rua das Paineiras, dentro do Campus 
da USP. Para isso o Sr. (a) receberá um mapa e explicações de como chegar, caso ainda não saiba.

\section{OS EXAMES SÃO DESCONFORTÁVEIS OU GERAM RISCOS?}

Toda pesquisa com seres humanos envolve risco em tipos e gradações variados. Devem ser analisadas possibilidades de danos imediatos ou posteriores, no plano individual ou coletivo (Resolução no 466, de 12 de dezembro de 2012).

Os exames propostos não causam nenhum prejuízo. Mas, existe um risco mínimo de o Sr. (a), por algum motivo que não conhecemos, sentir algum tipo de dor, desconforto ou cansaço nos músculos da rosto durante a realização dos exames. Caso isso aconteça, as examinadoras vão parar de fazer as avaliações. Depois, elas verão se é possível continuar os exames ou se serão agendados para outro dia ou ainda, se não serão mais realizados. As pesquisadoras manterão sigilo sobre a sua identidade e o Sr. (a) será esclarecido quanto aos procedimentos realizados e informado sobre os resultados que vamos ter com a pesquisa, sendo que tem total garantia de acesso aos resultados da pesquisa. $\mathrm{E}$ a qualquer momento, o Sr. (a) poderá desistir que esses dados sejam utilizados na presente pesquisa. Portanto, as pesquisadoras tomarão todos os cuidados possíveis em manter o sigilo a respeito da sua identidade e participação no estudo. Entretanto, caso o Sr. (a) sinta-se lesado, é de seu direito solicitar indenização, conforme legislação vigente.

\section{O PARTICIPANTE TERÁ GASTOS OU DESPESAS?}

Caso o Sr. (a) tenha que se locomover até o Laboratório de Fonoaudiologia para realização exclusiva dos exames da pesquisa, nós nos comprometemos a dar assistência e fornecer recursos para o transporte (valor em reais equivalente às passagens de ida de volta, seja de dentro de Ribeirão Preto ou de alguma cidade vizinha) e também quanto ao lanche que poderá ser disponibilizado antes ou após a realização dos exames, conforme solicitada e afirmada a necessidade. 
Nada será cobrado, assim como o Sr.(a) também não receberá qualquer benefício financeiro. As pesquisadoras se comprometem a prestar assistência integral no decorrer da pesquisa, se algum problema decorrer desta. A indenização, a título de cobertura material, para reparação de danos imediatos ou tardios, decorrentes da sua participação na pesquisa, caso ocorra, será realizada pelas pesquisadoras, não cabendo ao Hospital das Clínicas de Ribeirão Preto qualquer responsabilidade quanto aos referidos pagamentos.

\section{A PESQUISA TRARÁ ALGUM BENEFÍCIO PARA O PARTICIPANTE?}

Poderá trazer um benefício indireto, ou seja, se durante as avaliações feitas, forem identificadas alterações nos músculos da face, nos movimentos ou na articulação temporomandibular, os voluntários participantes receberão orientações e serão encaminhados aos tratamentos específicos caso necessitem.

\section{O QUE ACONTECE COM QUEM NÃO PARTICIPA DA PESQUISA?}

A sua participação no estudo é voluntária, não acarretando absolutamente nada ao Sr. (a) caso não aceite participar. O Sr. (a) tem a liberdade de se recusar a participar ou poderá interromper a pesquisa a qualquer momento, sem qualquer risco de prejuízos ou penalidades.

Concordando em participar da pesquisa o Sr. (a) assinará o Termo de Consentimento Livre e Esclarecido, o qual consta os dados das Pesquisadoras Responsáveis, para caso necessite de maiores informações, ou por qualquer outra necessidade e poderá entrar em contato a qualquer momento, assim como poderá entrar em contato com o Comitê de Ética em pesquisa do Hospital das Clínicas da Faculdade de Medicina de Ribeirão Preto caso tenha alguma reclamação, recurso ou dúvida, pelo telefone (16) 3602-2228. Dados da pesquisadora responsável para eventuais necessidades:

Fga. Monize Vilela 
End: Av. Bandeirantes, 3900, Monte Alegre, Ribeirão Preto, Cep: 14.049.900

Tel: (16) 3315-0592 (Laboratório de Fonoaudiologia).

Email:monize.vilela@hotmail.com

Pesquisadora: Participante:

Data: Data: 
ANEXO A

HOSPITAL DAS CLÍNICAS DA FACULDADE DE MEDICINA DE RIBEIRÃO PRETO DA UNIVERSIDADE DE SÃO PAULO

Oficio $n^{\circ} 939 / 2016$

$\mathrm{CEP} / \mathrm{MGV}$

PROCESSO HCRP $\mathrm{n}^{\circ} 17734 / 2015$

Prezadas Pesquisadoras,

O trabalho intitulado "BIOMIECÂNICA OROFACIAI NA PARALISIA FACIAL PrRTrÉriCA" - Projeto de Pesquisa Versão 2 - 11/03/2016, foi analisado pelo Comitê de Ética em Pesquisa, em sua $423^{a}$ Reunião Ordinária realizada em 14/03/2016, e enquadrado na categoria: APROVADO, bem como o Termo de Consentimento Livre e Esclarecido.

De acordo com Carta Circular $n^{\circ}$ 003/2011/CONEP/CNS, datada de 21/03/2011, o sujeito de pesquisa ou seu representante, quando for o caso, deverá rubricar todas as folhas do Termo de Consentimento Livre e Esclarecido - TCLE - apondo sua assinatura na última do referido Termo; o pesquisador responsável deverá da mesma forma, rubricar todas as folhas do Termo de Consentimento Livre e Esclarecido-TCLE - apondo sua assinatura na última página do referido Termo.

Este Comitê segue integralmente a Conferência Internacional de Harmonização de Boas Práticas Clínicas (IGH-GCP), bem como a Resolução $n^{\circ}$ 466/2012 CNS/MS.

Lembramos que devem ser apresentados a este CEP, o Relatório Parcial e o Relatório Final da pesquisa. Atenciosamente.

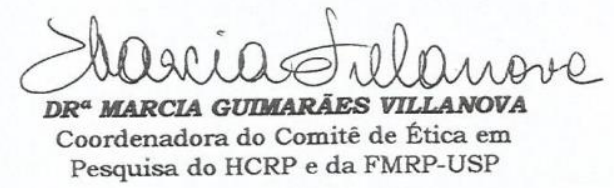

Ilustrissimas Senhoras MONEE VIELA.

PROF" DR LUCLANA VTALIANO VOI TRAWITZKI (Orientadora)

Depto. de Oftalmologia, Otorrinolaringologia e Cirurgia de Cabeça e Pescoço

HOSPITAL DAS CLINICAS DA FACULDADE DE MEDICINA DE RIBEIRĀO PRETO DA UNIVERSIDADE DE SÃO PAULO Campus Universitário - Monte Alecre Comitê de Ética em Pesquisa do HCRP e FMRP-USP Campus Universitário - Monte Alegr

Comitê de Ética em Pesquisa do HCRP e FMRP-USP FWA-00002733; IRB-00002186
Registro Plataforma Brasil /CONEP no (016) $3602-2228$

www.herp. usp.br 


\section{ANEXO B}

USP - HOSPITAL DAS
CLINICAS DA FACULDADE DE
MEDICINA DE RIBEIRÃO

\section{PARECER CONSUBSTANCIADO DO CEP}

DADOS DA EMENDA

Título da Pesquisa: Biomecânica Orofacial na Paralisia Facial Periférica

Pesquisador: Monize Vilela

Área Ten ática:

Versão: 3

CAAE: 50892015.8 .0000 .5440

Instituiçāo Proponente: UNIVERSIDADE DE SAO PAULO

Patrocinador Principal: Financiamento Próprio

DADOS DO PARECER

Número do Parecer: 3.087 .456

Apresentação do Projeto:

Trata-se de emenda ao projeto de pesquisa conforme carta datada de 10 de dezembro de 2018 .

Objetivo da Pesquisa:

Não modificado com a emenda.

Avaliação dos Riscos e Benefícios:

Não modificado com a emenda.

Comentários e Consideraçōes sobre a Pesquisa:

Justificativa da Emenda:

-Com o decorrer da pesquisa, concordamos que há a necessidade de mudança de título para a entrega da dissertação, pois o novo título se adequa mais ao estudo proposto." De: "Biomecânica Orofacial na Paralisia Facial Periférica" Para: "Desempenho orofacial e qualidade de vida na fase aguda da paralisia facial periférica".

Consideraçōes sobre os Term os de apresentação obrigatória:

Documentos apresentados na emenda:

- Relatorio.pdf;

- Emenda.pdf;

- Projeto_Versao_2.pdf.

UF: SP Municipio: RIBEIRAO PRETO

Telefone: (16)3602-2228 Fax: (16)3633-1144 E-mail: cep Qncrp.usp.br 


\section{USP - HOSPITAL DAS \\ CLIINICAS DA FACULDADE DE MEDICINA DE RIBEIRÃO}

Continuaçäo do Parecer. 3.087 .456

Recomendaçōes:

Nāo há.

Conclusōes ou Pendências e Lista de Inadequaçōes:

O CEP analisou e aprovou a emenda referente à mudança de título da pesquisa para -Desempenho orofacial e qualidade de vida na fase aguda da paralisia facial periférica". O CEP tomou ciência do relatório parcial.

Consideraçōes Finais a critério do CEP:

Este parecer foi elaborado baseado nos documentos abaixo relacionados:

\begin{tabular}{|c|c|c|c|c|}
\hline Tipo Documento & Arquivo & Postagem & Autor & Situaçāo \\
\hline $\begin{array}{l}\text { Informaçōes Básicas } \\
\text { do Projeto }\end{array}$ & $\begin{array}{l}\text { PB_INFORMAÇŌES_BASICAS_127037 } \\
3 \text { E1.pdf }\end{array}$ & $\begin{array}{c}10 / 12 / 2018 \\
13-24: 32\end{array}$ & & Aceito \\
\hline $\begin{array}{l}\text { Projeto Detalhado / } \\
\text { Brochura } \\
\text { Investigador }\end{array}$ & Relatorio.pdf & $\begin{array}{c}10 / 12 / 2018 \\
13: 22: 29\end{array}$ & Monize Vilela & Aceito \\
\hline Outros & Emenda.pdf & $\begin{array}{c}10 / 12 / 2018 \\
13-21: 43\end{array}$ & Monize Vilela & Aceito \\
\hline $\begin{array}{l}\text { Projeto Detalhado / } \\
\text { Brochura } \\
\text { Investigador }\end{array}$ & Projeto_Versao_2.pdf & $\begin{array}{c}10 / 03 / 2016 \\
22: 08: 48\end{array}$ & Monize Vilela & Aceito \\
\hline Outros & Cartaz_recrutamento.pdf & $\begin{array}{c}10 / 03 / 2016 \\
22: 08: 27\end{array}$ & Monize Vilela & Aceito \\
\hline Outros & Resposta_Parecer_CEP.pdf & $\begin{array}{c}10 / 03 / 2016 \\
22-08: 02\end{array}$ & Monize Vilela & Aceito \\
\hline Outros & UPC.pdf & $\begin{array}{c}10 / 12 / 2015 \\
17: 04: 01\end{array}$ & $\begin{array}{l}\text { MARCIA } \\
\text { GUIMARĀES } \\
\text { VILLANOVA }\end{array}$ & Aceito \\
\hline $\begin{array}{l}\text { Projeto Detalhado / } \\
\text { Brochura } \\
\text { Investigador }\end{array}$ & Projeto_biomecanica_orofacial.pdf & $\begin{array}{c}11 / 11 / 2015 \\
14: 42: 07\end{array}$ & Monize Vilela & Aceito \\
\hline $\begin{array}{l}\text { TCLE / Termos de } \\
\text { Assentimento / } \\
\text { Justificativa de } \\
\text { Ausência }\end{array}$ & TCLE.pdf & $\begin{array}{c}11 / 11 / 2015 \\
14: 38: 30\end{array}$ & Monize Vilela & Aceito \\
\hline Folha de Rosto & Folha_de_rosto.pdf & $\begin{array}{c}11 / 11 / 2015 \\
14: 33: 07\end{array}$ & Monize Vilela & Aceito \\
\hline
\end{tabular}

Situação do Parecer:

Aprovado

Endereco: CAMPUS UNIVERSITARIO

BairTo: MONTE ALEGRE

UF: SP Municipio: RIBEIRAO PRETO

Telefone: (16)3602-2228

Fax: (16)3633-114

E-mail: cep (ncrp.usp.br 


\begin{tabular}{|c|c|}
\hline$\underbrace{}_{\text {HCPP. FMPP }}$ & $\begin{array}{l}\text { USP - HOSPITAL DAS } \\
\text { CLINICAS DA FACULDADE DE Q protoforma } \\
\text { MEDICINA DE RIBEIRẪO }\end{array}$ \\
\hline
\end{tabular}

Necessita Apreciação da CONEP:

Não

RIBEIRAO PRETO, 17 de Dezembro de 2018

Assinado por:

MARCIA GUIMARĀES VILLANOVA

(Coordenador(a)) 